Ribeiro, F.; Sena-Cruz, J.; Branco, F.; Júlio, E. (2019) "3D finite element model for hybrid FRP-confined concrete in compression using modified CDPM.” Engineering Structures, 190: 459-479.

DOI: 10.1016/j.engstruct.2019.04.027

\title{
3D finite element model for hybrid FRP-confined concrete in compression using modified CDPM
}

\author{
Filipe Ribeiro ${ }^{1}$, José Sena-Cruz ${ }^{2 *}$, Fernando G. Branco ${ }^{3}$, Eduardo Júlio ${ }^{4}$
}

\begin{abstract}
:
The main goal of the work herein presented is to propose an accurate three-dimensional finite element model to predict the compressive behaviour of hybrid FRP-confined concrete. This was achieved through the modification of the concrete damaged plasticity model (CDPM) available in ABAQUS software, since the original CDPM has shortcomings that make it unusable to predict the compressive behaviour of confined concrete. It was demonstrated that, by turning the yield function and the flow rule dependents on the confining pressure, it is possible to use the model referred to and obtain accurate results.
\end{abstract}

An analytical model was used to obtain the input parameters needed to calibrate the CDPM. A specific user subroutine was developed to modify the original CDPM. Hybrid FRP properties were calibrated as well, using an appropriate analytical model. Plasticity was assumed in the hybrid combinations for which pseudo-ductile tensile responses occurred. The performance of the proposed CDPM was validated using both experimental results and analytical predictions.

It was concluded that, by using the developed 3D finite element model for hybrid FRP-confined concrete in compression, a very good agreement between experimental, analytical and numerical compressive stress-strain and lateral strain-axial strain curves is reached.

Keywords

Finite element (FE) analysis; Concrete Damaged Plasticity Model (CDPM); Hybrid FRP jacketing; Circular concrete columns; Concrete confinement.

\footnotetext{
${ }^{1}$ PhD Student, CERIS, Instituto Superior Técnico, Universidade de Lisboa, Portugal. E-mail: filipe.t.ribeiro@tecnico.ulisboa.pt

${ }^{2}$ Associate Professor, ISISE, Department of Civil Engineering, University of Minho, Portugal. E-mail: jsena@civil.uminho.pt*Corresponding Author

${ }^{3}$ Assistant Professor, ISISE, Department of Civil Engineering, University of Coimbra, Portugal. E-mail: fjbranco@dec.uc.pt

${ }^{4}$ Full Professor, CERIS, Instituto Superior Técnico, Universidade de Lisboa, Portugal. E-mail: eduardo.julio@tecnico.ulisboa.pt
} 
Ribeiro, F.; Sena-Cruz, J.; Branco, F.; Júlio, E. (2019) "3D finite element model for hybrid FRP-confined concrete in compression using modified CDPM.” Engineering Structures, 190: 459-479.

DOI: 10.1016/j.engstruct.2019.04.027

\section{INTRODUCTION}

In the last three decades, Fibre Reinforced Polymers (FRP) composites have been used as jackets in the confinement of concrete columns [1]. Today, it is known that FRP jackets allow concrete to reach higher compressive strength and higher ultimate axial and lateral strains, contributing to delay concrete cracking and preventing the relative displacement of disaggregated concrete pieces [2]. These confining systems are typically produced through the hand lay-up method [2]. Columns are retrofitted through FRP wrapping, positioning the fibres transversely oriented, relatively to the longitudinal axis of the column.

Although FRP systems have important advantages over traditional structural materials (such as lightweight, durability, high strength and stiffness), they also present a significant drawback: brittleness. In fact, a linear elastic behaviour up to failure is observed. For this reason, FRP-confined concrete submitted to pure compression fail abruptly, being this behaviour dominated by FRP failure. However, it was proved by Ribeiro et al. [3] that the drawback referred to can be mitigated through the hybridisation of reinforcing materials, i.e., by combining two different types of unidirectional (UD) dry fabrics in the same matrix (thus obtaining a hybrid FRP composite). If this combination of fibres is properly materialized, it is possible to promote synergies between the reinforcing materials, conducting, for instance, to pseudo-ductile tensile response (characterized by fragmentation in the low strain material and dispersed delamination, please see details in [4]), and an increase of the apparent failure strain of low strain fibres, known as 'hybrid effect'. Achieving pseudo-ductility may help composite structures to maintain functionality (even when they are overloaded) and to improve safety, thus enabling the reduction of the safety design factors.

Although there are already several examples of hybrid composite developed for civil engineering [5-23], the study of the same was initially motivated in the scope of aerospace and automotive industries [7, 24, 25]. Today, the last referred to industries continue to show the greatest interest in the subject. In this context, an exhaustive work to achieve pseudo-ductile tensile response with UD hybrid composites has been carried out [4, 26-31]. Research demonstrated that, to achieve pseudo-ductility in hybrid composites, two damage mechanisms should take place simultaneously, namely: (i) the fragmentation of the low strain (LS) material and (ii) the stable delamination of the low strain material from the high strain material layers close to the LS material fractures. The described properties of hybrid composites were explored, for the first time, in the confinement of small-scale circular concrete columns in the work of Ribeiro et al. [3]. In this work, it has been demonstrated that an analysisoriented confinement model, based on a modified approach of Lim and Ozbakkaloglu [32, 33] (incorporating the model of Jalalvand et al. [4] to simulate the tensile stress-strain curve of hybrid composite) allows to accurately 
Ribeiro, F.; Sena-Cruz, J.; Branco, F.; Júlio, E. (2019) "3D finite element model for hybrid FRP-confined concrete in compression using modified CDPM.” Engineering Structures, 190: 459-479.

DOI: 10.1016/j.engstruct.2019.04.027

simulate both the dilation behaviour and the compressive stress-strain behaviour of all hybrid confined concrete series analysed.

According to the author's knowledge, up to the current date, an accurate finite element (FE) model to predict the hybrid FRP-confined concrete compressive behaviour has not been developed yet. As it is known, such models allow modelling the three-dimensional behaviour of confined concrete subjected to complex stress states. This is important, for instance, to simulate non-circular FRP-confined columns, since in this case the confining pressure provided by the jacket is non-uniform and analytical analysis-oriented models developed for circular confined concrete columns cannot be readily used [34]. In case of FRP-confined concrete columns under eccentric loading, three-dimensional FE models allow as well to overcome the difficulties associated with laboratory studies, namely the lack of information about the interaction mechanism between FRP and concrete and the distribution of axial stress and confining pressure over the section [35].

Recently, modified plasticity-damage models [34-37], based on the proposed models of Lubliner et al. [38] and Lee and Fenves [39], have been suggested as the best models to predict axial compression responses of FRPconfined concrete columns. To achieve this goal, the confinement-dependent characteristics of FRP-confined concrete have to be incorporated into the yield function, flow rule, and damage variable [34]. These modifications have been implemented within the theoretical framework of the concrete damaged plasticity model (CDPM) available in ABAQUS software [40]. More specifically, it is common the use of lateral strain-to-axial strain analytical models to compute the dilation angle and, consequently, to modify the flow rule in function of confining pressure and axial strain. Besides, compressive stress-strain analytical models have been used to compute the effective compressive cohesion stress (also known as strain-hardening/softening rule) for different levels of confinement [34]. Finally, the damage variable, which allows simulating the reduction of elastic stiffness of concrete, has been computed as well in function of the confining pressure. However, it has been proved that, in case of monotonic compression tests simulation, this parameter has little effect on the predicted stress-strain curve of FRP-confined concrete [36].

The aim of the present work is to develop and apply a modified CDPM for hybrid FRP-confined columns. The analysis-oriented model for hybrid FRP-confined concrete presented in the work of Ribeiro et al. [3], based on models of Lim and Ozbakkaloglu $[32,33]$, is adopted to compute all the necessary input parameters of the CDPM. ABAQUS software [40] was used to perform all the simulations. The modifications in the yield surface and flow rule were made through a user subroutine in order to redefine the field variables at material points (USDFLD). This type of subroutine allows users to define the values of field variables (in the present case, the 
Ribeiro, F.; Sena-Cruz, J.; Branco, F.; Júlio, E. (2019) "3D finite element model for hybrid FRP-confined concrete in compression using modified CDPM.” Engineering Structures, 190: 459-479.

DOI: 10.1016/j.engstruct.2019.04.027

confining pressure and the axial strain) directly at the integration points of FE. This was accomplished using tabular input and a FORTRAN code to define the field variables. The proposed modifications to improve the CDPM are discussed in detail in the following sections. Comparisons with experimental and analytical results show that the predictions of the proposed model are in close agreement with measured parameters.

\section{CONCRETE DAMAGED PLASTICITY MODEL}

\section{$2.1 \quad$ Theoretical background}

The CDPM is a continuum plasticity-based damage model in which the concept of isotropic damaged elasticity in combination with isotropic plasticity is adopted [41]. In this way, the CDPM can be used for modelling the nonlinear deformation and irreversible damage, generally associated to cracking, of plain concrete with high accuracy [41]. As any other plasticity model, the CDPM depends on yield criterion, which is a mathematical description of the stresses under which yielding occurs (known as yield function), and the flow rule that establishes the general relations between plastic strains and the stress states.

The yield function is defined as follows:

$$
F=\frac{1}{1-A}\left(\sqrt{3 \bar{J}_{2}}-A \bar{I}_{1}+B\left\langle-\bar{\sigma}_{\text {min }}\right\rangle-C\left\langle\bar{\sigma}_{\text {min }}\right\rangle\right)-\bar{\sigma}_{c n}\left(\tilde{\varepsilon}_{p, c}\right)=0
$$

with

$$
\begin{aligned}
& A=\frac{\frac{f_{b}}{f_{c 0}}-1}{2 \frac{f_{b}}{f_{c 0}}-1} ; 0 \leq A<0.5 \\
& B=\frac{\bar{\sigma}_{c n}\left(\tilde{\varepsilon}_{p, c}\right)}{\bar{\sigma}_{t n}\left(\tilde{\varepsilon}_{p, t}\right)}(1-A)-(1+A) \\
& C=\frac{3(1-K)}{2 K-1}
\end{aligned}
$$

where $\bar{I}_{1}$ is the first effective stress invariant (see equation (5)) and $\bar{J}_{2}$ is the second effective deviatoric stress invariant (see equation (6)), the $\bar{\sigma}_{\min }$ is the minimum principal effective stress, $\langle\cdot\rangle$ denotes the Macauley bracket defined as $\langle x\rangle=(|x|+x) / 2, f_{\mathrm{b}}$ is the concrete strength under equal biaxial compression, $f_{\mathrm{c} 0}$ is the peak stress of the unconfined concrete, $\bar{\sigma}_{c n}$ and $\bar{\sigma}_{t n}$ are the effective compressive and tensile cohesion stresses respectively, $\tilde{\varepsilon}_{p, c}$ and $\tilde{\varepsilon}_{p, t}$ are the equivalent compressive and tensile plastic strains respectively, and $K$ is the strength ratio of concrete under equal biaxial compression to triaxial compression. It should be highlighted that throughout this work the soil mechanics sign convention is adopted, whereby compressive stresses/strains are considered positive while tensile stresses/strains are considered negative. 
Ribeiro, F.; Sena-Cruz, J.; Branco, F.; Júlio, E. (2019) "3D finite element model for hybrid FRP-confined concrete in compression using modified CDPM.” Engineering Structures, 190: 459-479.

DOI: 10.1016/j.engstruct.2019.04.027

$$
\begin{aligned}
& \bar{I}_{1}=\bar{f}_{c}+\bar{f}_{l, 1}+\bar{f}_{l, 2} \\
& \bar{J}_{2}=\frac{\left(\bar{f}_{c}-\bar{f}_{l, 1}\right)^{2}+\left(\bar{f}_{l, 2}-\bar{f}_{l, 1}\right)^{2}+\left(\bar{f}_{l, 2}-\bar{f}_{c}\right)^{2}}{6}
\end{aligned}
$$

where $\bar{f}_{c}$ is the effective principal compressive stress, $\bar{f}_{l, 1}$ and $\bar{f}_{l, 2}$ are the effective principal lateral stresses. Please note that, in the present work, only the case of triaxial compression is being considered.

The term effective stress is used because all the stress quantities are understood as:

$$
\bar{f}_{i j}=\frac{f_{i j}}{1-d_{i j}}
$$

where $\bar{f}_{i j}$ is the effective stress tensor, $f_{\mathrm{ij}}$ is the stress tensor (see equation (8)), and $d_{i j}$ is the damage tensor which characterizes the degradation of the elastic stiffness.

$$
f_{i j}=\left(1-d_{i j}\right) D_{i j k l}^{e}\left(\varepsilon_{i j}-\varepsilon_{i j}^{p}\right)
$$

where $\varepsilon_{i j}$ and $\varepsilon_{i j}^{p}$ are the strain and the plastic strain tensors and $D_{i j k l}^{e}$ is the initial (undamaged) elasticity matrix.

For concrete with a constant confining pressure, the damage tensor is reduced to the compressive damage parameter [34]:

$$
d_{c}=1-\frac{f_{c}-\frac{1+C+2 A}{1-A} f_{l}}{f_{c c}^{*}-\frac{1+C+2 A}{1-A} f_{l}}
$$

where $f_{\mathrm{c}}$ is the compressive stress of concrete, $f_{1}$ is the confining pressure, and $f_{c c}^{*}$ is the peak stress of actively confined concrete and can be estimated using equation (10) $[32,42]$ :

$$
f_{c c}^{*}=f_{c 0}+5.2 f_{c 0}^{0.91}\left(\frac{f_{l}}{f_{c 0}}\right)^{a} \text { where } a=f_{c 0}{ }^{-0.06}
$$

In the work of Hany et al. [36], it was stated that damage parameter has significant effect on the stressstrain curve when FRP-confined concrete is subjected to cyclic loading, but it is negligible for monotonic loading situations. In the present work, two scenarios were tested: (i) to adopt the damage parameter, according to equation (9), and (ii) to neglect the damage parameter. It was confirmed that, in both situations, no significant differences occurred. However, the damage parameter, computed according equation (9), was implemented in the final model.

The flow rule, $d \varepsilon_{i j}^{p}$, that defines the direction of plastic deformation and dictates the evolution of dilation behaviour of concrete is non-associated:

$$
d \varepsilon_{i j}^{p}=\frac{\delta G}{\delta \sigma_{i j}}
$$

where $G$ is the Drucker-Prager hyperbolic function, defined by equation (12): 
Ribeiro, F.; Sena-Cruz, J.; Branco, F.; Júlio, E. (2019) "3D finite element model for hybrid FRP-confined concrete in compression using modified CDPM.” Engineering Structures, 190: 459-479.

DOI: 10.1016/j.engstruct.2019.04.027

$$
G=\sqrt{\left(\ni \sigma_{t 0} \tan \Psi\right)^{2}+3 \bar{J}_{2}^{2}}-\frac{\bar{I}_{1}}{3} \tan \Psi
$$

where $\sigma_{\mathrm{to}}$ is the uniaxial tensile stress at failure; $\ni$ is the eccentricity parameter, and $\Psi$ is the plastic dilation angle, according to equation (13):

$$
\tan \Psi=-\frac{3\left(\varepsilon_{c, p}+2 \varepsilon_{l, p}\right)}{2\left(\varepsilon_{c, p}-\varepsilon_{l, p}\right)}
$$

where $\varepsilon_{c, p}$ is the axial plastic strain and $\varepsilon_{l, p}$ the lateral plastic strain.

For actively confined concrete, the referred plastic strains can be computed according to equations (14) and (15) [37]:

$$
\begin{aligned}
& \varepsilon_{c, p}=\varepsilon_{c}-\frac{1}{E_{c}}\left(f_{c}-2 v_{i} f_{l}\right) \\
& \varepsilon_{l, p}=\varepsilon_{l}-\frac{1}{E_{c}}\left(\left(1-v_{i}\right) f_{l}-v_{i} f_{c}\right)
\end{aligned}
$$

where $E_{\mathrm{c}}$ is the elastic modulus of plain concrete and $v_{\mathrm{i}}$ is the initial Poisson's ratio of concrete $\left(\varepsilon_{1} / \varepsilon_{\mathrm{c}}\right)[43]$ :

$$
v_{i}=8 \times 10^{-6} f_{c 0}^{2}+0.0002 f_{c 0}+0.138
$$

For concrete under non-uniform confinement, the confining pressure should be computed using the equation (17) [34]:

$$
f_{l}=\frac{2\left(f_{l, 1}+0.039 f_{c 0}\right)\left(f_{l, 2}+0.039 f_{c 0}\right)}{f_{l, 1}+f_{l, 2}+2 \times 0.039 f_{c 0}}-0.039 f_{c 0}
$$

In the present work, since the compressive behaviour of confined small-scale plain circular concrete columns is analysed, it is expected that $f_{1}=f_{1,1}=f_{1,2}$. However, equation (17) was implemented in the final model in order to turn the same capable of simulate the compressive behaviour of concrete under non-uniform confinement.

\subsection{Proposed modifications}

It has been stated that original CDPM is not successful in predicting the compressive behaviour of actively confined concrete and, consequently, the passively confined concrete $[34,36,37]$. This is due to the fact that a unique stress-strain curve of plain concrete cannot be used to define the compressive cohesion stress, $\bar{\sigma}_{c n}$, or, in other words, the hardening rule of concrete. As discussed in Section 2.2.1, the hardening rule has to be dependent on the confining pressure, which leads to the modification of the original yield function. Furthermore, the plastic dilation angle should vary in function of lateral strain-axial strain curve, as discussed in Section 2.2.2.

\subsubsection{Hardening/softening rule}


Ribeiro, F.; Sena-Cruz, J.; Branco, F.; Júlio, E. (2019) "3D finite element model for hybrid FRP-confined concrete in compression using modified CDPM.” Engineering Structures, 190: 459-479.

DOI: 10.1016/j.engstruct.2019.04.027

In the present subsection, the modification of the hardening rule is proposed. Numerical predictions are compared with analytical results obtained through the stress-strain model for actively and passively confined concrete of Lim and Ozbakkaloglu [33]. These were computed according to both equation (18), proposed by Popovics [44], and equation (19), proposed by Lim and Ozbakkaloglu [33]:

$$
\begin{aligned}
& f_{c}=\frac{f_{c c}^{*}\left(\varepsilon_{c} / \varepsilon_{c c}^{*}\right) r}{r-1+\left(\varepsilon_{c} / \varepsilon_{c c}^{*}\right)^{r}}, \text { if } 0 \leq \varepsilon_{c} \leq \varepsilon_{c c}^{*} \\
& f_{c}=f_{c c}^{*}-\frac{f_{c c}^{*}-f_{c, r e s}}{1+\left(\frac{\varepsilon_{c-}-\varepsilon_{c c}^{*}}{\varepsilon_{c, i}-\varepsilon_{c c}^{*}}\right)^{-2}}, \text { if } \varepsilon_{c}>\varepsilon_{c c}^{*}
\end{aligned}
$$

where $f_{\mathrm{c}}$ and $\varepsilon_{\mathrm{c}}$ are the compressive stress and the axial strain of confined concrete, $\varepsilon_{c c}^{*}$ is the peak strain of actively confined concrete [32, 42], $r$ is the concrete brittleness [45], $f_{\text {c,res }}$ is the residual stress, and $\varepsilon_{c i}$ is the axial strain corresponding to the inflection point of the descending branch of stress-strain curve [33]. These last parameters are defined in the next equations:

$$
\begin{aligned}
& \varepsilon_{c c}^{*}=\varepsilon_{c 0}+0.045\left(\frac{f_{l}}{f_{c 0}}\right)^{1.15} \\
& r=\frac{E_{c}}{E_{c}-f_{c c}^{*} / \varepsilon_{c c}^{*}} \\
& f_{c, r e s}=1.6 f_{c c}^{*}\left(\frac{f_{l}^{0.24}}{f_{c 0}{ }^{0.32}}\right) \text { and } f_{c, r e s} \leq f_{c c}^{*}-0.15 f_{c 0} \\
& \varepsilon_{c, i}=2.8 \varepsilon_{c c}^{*}\left(\frac{f_{c, r e s}}{f_{c c}^{*}}\right) f_{c 0}^{-0.12}+10 \varepsilon_{c c}^{*}\left(1-\frac{f_{c, r e s}}{f_{c c}^{*}}\right) f_{c 0}^{-0.47}
\end{aligned}
$$

In equation (20), $\varepsilon_{\mathrm{c} 0}$ is the axial strain at the peak stress of the unconfined concrete $\left(f_{c 0}\right)$ given by [32]:

$$
\varepsilon_{c 0}=\left(-0.067 f_{c 0}^{2}+29.9 f_{c 0}+1053\right) \times 10^{-6}
$$

In equation (21), $E_{\mathrm{c}}$ is defined according to the next equation [33]:

$$
E_{c}=4400 \sqrt{f_{c 0}}
$$

The model of Lim and Ozbakkaloglu [33] was used to define the compressive stress-strain curve of plain concrete, i.e., the material input data of the numerical model that gave rise to the results of Figure 1 (a), assuming $f_{\mathrm{c} 0}=33.49 \mathrm{MPa}$ and $f_{1}=0 \mathrm{MPa}$. Four levels of constant confining pressure were considered in both models (numerical and analytical): 5, 10, 20, and $30 \mathrm{MPa}$. This range was selected because it is intended to validate the proposed FE model against experimental results published in a previous work by the authors [3]. In the mentioned work, it is possible to observe that the ultimate confining pressure in tested specimens varied between 6 and 26 $\mathrm{MPa}$, approximately. These values are within the considered range. The detailed description of the several parameters and assumptions used in FE modelling is present in Section 3. 
Ribeiro, F.; Sena-Cruz, J.; Branco, F.; Júlio, E. (2019) "3D finite element model for hybrid FRP-confined concrete in compression using modified CDPM.” Engineering Structures, 190: 459-479.

DOI: 10.1016/j.engstruct.2019.04.027

In Figure 1 (a) it is possible to observe that the shape of the numerical curves is the same for the different levels of confining pressure. According to the original CDPM, the increase of the confining pressure imposes a vertical and horizontal translation of the compressive stress-strain curve. The former is dependent on the yield function, and the latter is defined by the elastic modulus of plain concrete, i.e., since the axial stress increases with the increase of the confining pressure, the initial elastic branch is prolonged, leading to the observable lateral translation of the initial stress-strain curve.

In Figure 1 (a) it is also demonstrated that original CDPM leads to inaccurate predictions of actively confined concrete compressive behaviour, for the presented levels of confining pressure. It should be noted that a large number of actively confined and FRP-confined specimen results were used in the development of the presented stress-strain analytical model. It was proved that the analytical model provides improved predictions when compared to the previous models presented in the literature, see the details in [32, 33]. For this reason, it was expected that the numerical curve matched the analytical one.

Due to the lack of the observed accuracy between the numerical and analytical curves, it is mandatory to turn the hardening rule dependent of the confining pressure in order to correct the results. In ABAQUS software [40] the introduction of the hardening rule is made in tabular format. To turn the hardening rule dependent on the confining pressure, several compressive stress-strain curves have to be defined in function of specific values confining pressure. The last is considered a field variable that should be specified through USDFLD subroutine, programmed in FORTRAN language. Furthermore, the elastic modulus has to be modified, as well, in function of the confining pressure. The following procedure was used to correct the hardening rule:

i. The stress-strain analytical model, presented in equations (18) and (19), is used to define the expected compressive stress-strain curves of plain concrete subjected to different levels of constant confining pressure;

ii. The yield function, presented in equation (1), is used to define the value of $f_{\mathrm{c}}$ when the effective compressive cohesion stress is equal to zero;

iii. An actual elastic modulus is computed dividing the $f_{\mathrm{c}}$ value (obtained in step ii) by the corresponding strain.

iv. The strain that corresponds to the $f_{\mathrm{c}}$ value (obtained in step ii) is subtracted to all strain values of the compressive stress-strain curve computed in step i;

v. The $f_{\mathrm{c}}$ value (obtained in step ii) is subtracted to all stress values of the compressive stress-strain curve defined in step i; 
Ribeiro, F.; Sena-Cruz, J.; Branco, F.; Júlio, E. (2019) "3D finite element model for hybrid FRP-confined concrete in compression using modified CDPM.” Engineering Structures, 190: 459-479.

DOI: 10.1016/j.engstruct.2019.04.027

vi. Since the strain that corresponds to the $f_{\mathrm{c}}$ value (defined in step ii) is a positive value and the same is subtracted to all strain values of stress-strain curve, negative strain values results from step iv. In this step, negative values are deleted.

It should be noted that the presented procedure is different from all others found in published studies. In the present work, the perfectly-plastic behaviour assumption used by Yu et al. [34] is assumed as well, i.e., after the peak stress, the stress-strain curve is truncated and the yield function remains unchanged. This option has implications in the dilation concrete behaviour predictions. If a complete stress-curve curve was considered, it would not be possible to control the concrete dilation behaviour.

In Figure 1 (b) the numerical results obtained after the correction are presented and compared against analytical ones. It is possible to observe that after an initial branch, that was intentionally assumed as elastic, there is a perfect match between numerical and analytical curves until the peak stress is reached.

\subsubsection{Flow rule}

Many authors have used the CDPM assuming a constant $\Psi$ [46-52]. However, this assumption does not lead to accurate prediction of the dilation behaviour (lateral strain-axial strain curves) of actively confined concrete, as demonstrated in Figure 2 (a). In this case, a constant $\Psi=35^{\circ}$ was assumed to obtain the lateral strainaxial strain numerical curves. As it is possible to observe, the last assumption leads to confining pressure having only a residual influence on the numerical curve developing. Therefore, all numerical curves are almost coincident and differ substantially from the analytical ones (presented as well in Figure 2 (a)). The last was obtained with the model proposed by Lim and Ozbakkaloglu [32], see equation (26):

$$
\varepsilon_{c}=\frac{\varepsilon_{l}}{v_{i}\left[1+\left(\frac{\varepsilon_{l}}{v_{i} \varepsilon_{c 0}}\right)^{n}\right]^{1 / n}}+0.04 \varepsilon_{l}^{0.7}\left[1+21\left(\frac{f_{l}}{f_{c 0}}\right)^{0.8}\right]
$$

where $n$ is the curve shape parameter:

$$
n=1+0.03 f_{c 0}
$$

The analytical model was developed based on large database of unconfined and actively confined concrete results, please see the details in [32]. It was also proved that the model is able to predict the dilation behaviour of hybrid FRP confined concrete, please see details in [3].

Figure 2 (a) also shows that the numerical predictions of dilation behaviour of actively confined concrete are not in agreement with analytical ones. For this reason, they need to be corrected. This can be done considering the evolution of $\Psi$, according to equation (13). In Figure 3 the referred evolution of $\Psi$ is presented as a function 
Ribeiro, F.; Sena-Cruz, J.; Branco, F.; Júlio, E. (2019) "3D finite element model for hybrid FRP-confined concrete in compression using modified CDPM.” Engineering Structures, 190: 459-479.

DOI: 10.1016/j.engstruct.2019.04.027

of axial plastic strain (see equation (14)) for the considered levels of confining pressure. It is important to note that, according to the sign convention, lateral strain was considered negative and axial strains positive in the computation of $\Psi$.

Similarly to what was stated for the hardening rule, in ABAQUS software [24] the introduction of $\Psi$ is also carried out in tabular format. However, the software only admits values of $\Psi$ between $0.1^{\circ}$ and $56^{\circ}$. This limitation implies that, even with the modification of $\Psi$, a precise dilation behaviour of confined concrete cannot be simulated. Since $\Psi$ is negative in some cases and higher than $56^{\circ}$ in others, it is possible to observe in Figure 2 (b) that there are still some mismatches between numerical and analytical curves. However, the suggested modifications proved to be sufficient to reach good predictions of hybrid FRP confined concrete behaviour, as it demonstrated in Section 4.

\section{FINITE ELEMENT (FE) MODELLING}

\subsection{Experimental database}

In the present work, experimental results obtained in monotonic uniaxial compression tests of 60 cylindrical specimens, comprising 48 hybrid FRP-confined and 12 non-hybrid FRP-confined specimens, are compared with numerical predictions obtained with the suggested modified CDPM. Each tested specimen was $150 \mathrm{~mm}$ in diameter and $300 \mathrm{~mm}$ in height. The experimental variables included (i) the LS fibres relative volume (vol\%) and (ii) the type of FRP of jacket, i.e., jackets made with different combinations of reinforcing materials. The details of the experimental results can be found in [3].

Four types of dry UD fabrics were used to produce the FRP jackets: UD HM carbon (S\&P C-Sheet 640), ST carbon (S\&P C-Sheet 240), E-glass (S\&P G-sheet E 90/10), and basalt (Dalla Betta Group U400B-40-50-03) fabrics. In Table 1 the density, areal mass, fibre layer thickness (areal mass density divided by the volumetric mass density) and the basic tensile properties of the mentioned materials are presented. For each dry fabric, a large number of single fibres (see the details in Table 1) were randomly taken from the dry fabrics and tested in uniaxial tension, according to ASTM D3379-75 [53].

The tensile properties of 1 layer non-hybrid composites, determined according to ISO 527-5:2009 [54], are also presented in Table 1. All the composites referred to in the present work were laminated using an epoxy-based resin (S\&P Resin Epoxy 55). According to the supplier, this epoxy resin has the following main properties [55]: (i) $35.8 \mathrm{MPa}$ tensile strength; (ii) $2.3 \%$ strain failure; and (iii) of 2.6 GPa elastic modulus. 
Ribeiro, F.; Sena-Cruz, J.; Branco, F.; Júlio, E. (2019) "3D finite element model for hybrid FRP-confined concrete in compression using modified CDPM.” Engineering Structures, 190: 459-479.

DOI: 10.1016/j.engstruct.2019.04.027

In Table 1, it is possible to observe that tensile strength and, consequently, the elastic modulus of nonhybrid composites are higher than the values obtained for single fibres. This is due to the fact that, in the case of composites, the tensile properties were evaluated ignoring the contribution of the resin, according to the usual practice of the wet lay-up method and guidelines [56]. This means that tensile strength was computed considering only the dry fabric thickness, thus leading to overestimation of the tensile strength.

Relatively to hybrid combinations, 16 series were considered in the confinement application: 10 combinations with 3 reinforcing material layers and 6 combinations with 5 reinforcing material layers. Each series was composed of 3 specimens of confined concrete. Specimens with 5 layers were tested only on 2 hybrid combinations: HM carbon/glass and ST carbon/glass.

In addition to hybrid series, 4 series of 3 layer non-hybrid composites ( 1 for each reinforcing material) were produced. All specimens involved in the experimental campaign are listed in Table 2. In the present work, regarding composite materials nomenclature, numbers placed before letters are used for indicating the number of layers. The sequence according to which these letters appear indicate the stacking sequence of the reinforcing materials. The relative volume of LS fibres $($ Vol\% LS) was computed and presented in the next section, according to equation (28):

$$
\text { Vol\% } L S=\frac{t_{L}}{t_{L}+t_{H}} \times 100
$$

where $t_{\mathrm{L}}$ is the half thickness of the LS layers and $t_{\mathrm{H}}$ is the half thickness of the HS layers.

\subsection{Geometry, element types and meshing}

Taking into account the double symmetry of both the loading and the specimen, only a quarter of cylinders was modelled, as illustrated in Figure 4.

Two different FE types (three dimensional 8-node linear bricks with reduced integration (C3D8R) and 4node shell elements with reduced integration (S4R)) were used to discretize the concrete cylinders and the FRP jacket, respectively.

Care was taken to ensure that the mesh had, as much as possible, a regular geometry. Several decreasing mesh sizes were studied to evaluate the convergence of the model. It was concluded that elements with edges of about $8 \mathrm{~mm}$ provide accurate solutions. 
Ribeiro, F.; Sena-Cruz, J.; Branco, F.; Júlio, E. (2019) "3D finite element model for hybrid FRP-confined concrete in compression using modified CDPM.” Engineering Structures, 190: 459-479.

DOI: 10.1016/j.engstruct.2019.04.027

\subsection{Boundary conditions and interactions}

Traditionally, in uniaxial compression tests of concrete specimens, the load is applied through rigid steel plates. In this way, it is inevitable frictional forces to occur at the concrete-steel interface. These forces lead to the development of a stress field which restrains the transverse expansion of concrete within the end regions of specimens [57].

In this section, it is discussed if the detail of surface-to-surface contact (steel-concrete) should or should not be considered in the numerical model. Thus, two scenarios were considered in the simulation of compressive behaviour of plain concrete:

- In the first scenario, three dimensional steel plates with the same cross section as concrete and $50 \mathrm{~mm}$ of thickness were assembled to the ends of the concrete core. C3D8R elements were used to discretize the steel plates. It was assumed that these elements are rigid. A friction model to define the force resisting relative to tangential motion between concrete and steel plates was specified. A friction coefficient of 0.1 was assumed, according the recommendation suggested in the guideline [58]. In normal direction (i.e., in the loading direction) a hard contact was defined. It was concluded that the consideration of end restrains leads to highly non-uniform distribution of lateral displacements, as shown in Figure 5 (a). It is possible to observe that at middle height of the cylinder, the lateral deformation is maximum. The presented values of lateral displacement are relative to the peak axial stress of plain concrete;

- In the second scenario, the end restrains were not detailed. This leads to uniform distribution of lateral displacement, as shown in Figure 5 (b). It is possible to observe that the values of lateral displacement are approximately $14 \%$ lower than the ones observed in the first scenario, comparing the middle sections, for the same axial displacement.

It should be noted that, in both scenarios, compatible boundary conditions with the simplifications of the geometry assumed in the model were defined, i.e., lateral displacement restraints were applied orthogonally to the sliced faces. Axial displacements were restrained in the base of the model and uniformly imposed on the top the latter. Again, the model of Lim and Ozbakkaloglu [33] was used to define the compressive stress-strain curve of plain concrete, assuming $f_{\mathrm{c} 0}=33.49 \mathrm{MPa}$ and $f_{1}=0.00 \mathrm{MPa}$.

Analytical axial stress-strain curves are compared with numerical ones in Figure 6. Since the analytical model of Lim and Ozbakkaloglu [33] was used to define compressive stress-strain curve of plain concrete and 
Ribeiro, F.; Sena-Cruz, J.; Branco, F.; Júlio, E. (2019) "3D finite element model for hybrid FRP-confined concrete in compression using modified CDPM.” Engineering Structures, 190: 459-479.

DOI: 10.1016/j.engstruct.2019.04.027

there is no other action on the concrete than axial compression (in the case frictional forces were not contemplated), it was expected that both numerical and analytical curves were coincident.

It is possible to conclude that end restraints have no influence in the pre-ultimate compressive response of concrete and strength predictions but the post peak behaviour of concrete is dependent of friction between concrete and steel plates.

It should be highlighted that the analytical model of Lim and Ozbakkaloglu [33] was calibrated from experimental results in which the influence of end restrains were not suppressed. In this way, the obtained stressstrain curve implicitly considers the effect of end restrains. For this reason, it is not correct to consider the detail of end restrains in the numerical model, if the referred to analytical model is used to obtain the material input parameters of concrete. Otherwise, the end restraints effect would be contemplated twice.

Due to the above reasons, the influence of end restrains were not explicitly considered in the present work.

\subsection{Plasticity parameters}

Beyond hardening and flow rules, there are several parameters that have to be specified in order to use the CDPM, namely $\ni, f_{\mathrm{b}} / f_{\mathrm{c} 0}$, viscosity, and $K$.

According to published studies $[34,35,59], \exists$ and $f_{\mathrm{b}} / f_{\mathrm{c} 0}$ should be defined as 0.00 and 1.16 , respectively. The definition of $\ni$ as null implies that the potential function tends to a straight line. In this way, the strategy exposed in section 2.2.2 to compute $\Psi$ and to predict the dilation behaviour of concrete is valid. According to the work of Kupfer et al. [60], $f_{\mathrm{b}} / f_{\mathrm{c} 0}$ assumes a constant value of 1.16 . However, in the work of Papanikolaou and Kappos [61] it was suggested that $f_{\mathrm{b}} / f_{\mathrm{c} 0}$ should vary according to equation (29):

$$
\frac{f_{b}}{f_{c 0}}=1.5 \times f_{c 0}^{-0.075}
$$

According to this equation, if $f_{\mathrm{c} 0}$ varies between 19 and $30 \mathrm{MPa}, f_{\mathrm{b}} / f_{\mathrm{c} 0}$ will vary approximately between 1.16 and 1.20. Teng et al. [59] found that, within this range, the variation of $f_{\mathrm{b}} / f_{\mathrm{c} 0}$ has no significant effect on the numerical predictions. Due to the lack of information about the subject, and taking into account that 1.16 is the most used value in published studies, it was decided to maintain this value in the present work.

Few studies $[36,62]$ on the viscosity parameter state that it has residual influence on the prediction's accuracy. For this reason, this parameter was ignored in the present work. 
Ribeiro, F.; Sena-Cruz, J.; Branco, F.; Júlio, E. (2019) "3D finite element model for hybrid FRP-confined concrete in compression using modified CDPM.” Engineering Structures, 190: 459-479.

DOI: 10.1016/j.engstruct.2019.04.027

Although the influence of $K$ on the compressive behaviour predictions of confined concrete was studied in the present work, since only triaxial compression situations are analysed, a simplification of equation (1) was adopted [34]:

$$
\left(\frac{1}{3} C+1\right) \sqrt{3 \bar{J}_{2}}-\frac{(C+3 A)}{3} \bar{I}_{1}=(1-A) \bar{\sigma}_{c n}
$$

This equation is known as Drucker-Prager yield function and it defines a conic yield surface in the principal stress space, as presented in Figure 7 (a). It is possible to observe that changing the value of $K$ leads to substantial changes in the diameter of the yield surface, as seen for instance in the deviatoric plane defined as $\bar{I}_{1} / 3=100$ (see Figure 7 (b)).

In Figure 8, it is possible to observe that, for a constant level of confining pressure $\left(f_{1}=f_{1,1}=f_{1,2}\right)$, the peak stress of confined concrete $\left(f_{c c}^{*}\right)$ decreases with the increase of $K$. A sensitivity analysis was carried out to find out the value of $K$ leading to lowest initial prediction errors of the peak stress of actively confined concrete. From this analysis, it was concluded that $K=0.68$ leads to the lowest differences between unmodified CDPM and analytical peak stress predictions. For this reason, this value (0.68) was assumed in the present work.

\subsection{Material properties}

\subsubsection{FRP}

In a unidirectional (UD) hybrid FRP submitted to uniaxial tension, the first damage mode is always the failure of the LS fibres. However, other damage modes depend on the properties and configuration of the composite reinforcing materials [28]. The analytical approach proposed by Jalalvand et al. [4], validated in the scope of the present work in [63], considers that four different damage modes may occur after LS fibres failure: (i) premature HS failure, (ii) unstable delamination, (iii) LS layer fragmentation, and (iv) combination of LS fragmentation with stable delamination. For each hybrid configuration, three stress levels can be computed [4]: (i) the stress at which the first crack in the LS material occurs, $\sigma @ L F$, (ii) the stress at which delamination starts, $\sigma @ d e l$, and (iii) the stress at which the HS material fails, $\sigma @ H F$, in accordance with equations (31) to (33), respectively.

$$
\begin{aligned}
& \sigma @ L F=S_{L} \frac{\alpha \beta+1}{\alpha(\beta+1)} \\
& \sigma @ d e l=\frac{1}{1+\beta} \sqrt{\left(\frac{1+\alpha \beta}{\alpha \beta}\right)\left(\frac{2 G_{I I C} E_{H}}{t_{H}}\right)} \\
& \sigma @ H F=\frac{1}{(1+\beta)} \frac{S_{H}}{K_{t} \sqrt[m_{H}]{V}}
\end{aligned}
$$


Ribeiro, F.; Sena-Cruz, J.; Branco, F.; Júlio, E. (2019) "3D finite element model for hybrid FRP-confined concrete in compression using modified CDPM.” Engineering Structures, 190: 459-479.

DOI: 10.1016/j.engstruct.2019.04.027

where $S_{\mathrm{L}}$ is the reference strength of the LS material, $\alpha$ and $\beta$ are respectively the elastic modulus and thickness ratios of the LS to HS fibre, $G_{I I C}$ is the mode II interlaminar fracture toughness of the interface between LS layers and HS layers of the hybrid composite, $E_{\mathrm{H}}$ is the elastic modulus of the HS fibres, $t_{H}$ is the half thickness of the HS fibre, $m_{H}$ is the Weibull strength distribution modulus of the HS fibre, $S_{\mathrm{H}}$ is the reference strength of the HS material, $K_{t}$ is the stress concentration factor in the high strain material, and $V$ is the volume of the specimen (free length $\times$ width $\times$ total fibre layer thickness). The details of the adopted parameters are fully discussed in [63].

Knowing the magnitude of all three possible stresses allows assessing their order of occurrence and, consecutively, the identification of the damage modes, according to Table 3. In the present case, the studied combinations of materials (presented in Table 4) lead to the appearance of 3 damage modes, namely premature failure, catastrophic delamination and combination of fragmentation of LS material and dispersed delamination. When the last damage mode occurs, the behaviour of hybrid composite is pseudo-ductile because a flat-topped stress-strain curve is achieved.

As it has been exposed in [63], the damage mode of 2G/1CHM/2G, 1G/1CHM/1G, 1B/1CHM/1B and $1 \mathrm{C} / 1 \mathrm{CHM} / 1 \mathrm{C}$ series was combination of fragmentation and dispersed delamination and, in the case of $1 \mathrm{G} / 1 \mathrm{CHM} / 1 \mathrm{G} / 1 \mathrm{CHM} / 1 \mathrm{G}$ and $1 \mathrm{G} / 3 \mathrm{CHM} / 1 \mathrm{G}$ series, catastrophic delamination occurred. In the remaining cases, the damage mode was premature failure.

After the determination of the damage modes, it is possible to plot the tensile stress-strain curve of hybrid FRP. Five stress-strain coordinates are sufficient to define all possible tensile stress-strain curves of hybrid FRP, see Figure 9. The sets of coordinates that define the stress-strain curves for all the studied combinations are presented in Table 4. Please note that, when premature failure occurs, only the linear elastic branch is defined with two sets of stress-strains coordinates.

The FRP properties were specified using "Lamina" material type [40] in which the elastic modulus in the fibre direction is defined in accordance with the value provided in Table 1, in case of non-hybrid confinement, and Table 4, in case of hybrid confinement. In the orthogonal direction, an almost null elastic modulus $(0.001$ GPa) was assigned, and the Poisson's ratio was set equal to zero. Tie constraint was used to model the interaction between FRP jackets and concrete.

For all non-hybrid as well as for hybrid composites in which premature failure occurred, only elastic properties were defined. For the remaining cases, a plastic behaviour was defined using as input the coordinates exposed in Table 4. In these cases, strains have to be converted first in plastic strains, according to equation (34): 
Ribeiro, F.; Sena-Cruz, J.; Branco, F.; Júlio, E. (2019) "3D finite element model for hybrid FRP-confined concrete in compression using modified CDPM.” Engineering Structures, 190: 459-479.

DOI: 10.1016/j.engstruct.2019.04.027

$$
\varepsilon_{t, \text { hybrid }}^{p l}=\varepsilon_{t, \text { hybrid }}-\sigma_{\text {hybrid }} / E_{\text {hybrid }}
$$

where $\varepsilon_{t, h y b r i d}^{p l}$ is the tensile plastic strain, $\varepsilon_{t, \text { hybrid }}$ is the total tensile stain, $\sigma_{\text {hybrid }}$ is the tensile stress, and $E_{\text {hybrid }}$ is the elastic modulus of hybrid composite.

All simulations carried out showed that the tensile behaviour of both $1 \mathrm{G} / 1 \mathrm{CHM} / \mathrm{G} / 1 \mathrm{CHM} / 1 \mathrm{G}$ and $1 \mathrm{G} / 3 \mathrm{CHM} / 1 \mathrm{G}$ series has to be defined as linear elastic, otherwise the numerical analysis will abort. This is due to the fact that the stress drop that occurs in the stress-strain curve of these series leads to convergence errors.

\subsubsection{Concrete}

A ready-mix concrete was used in the experimental campaign [3]. The experimental campaign of the confined concrete specimens herein described was conducted in 15 consecutives working days. During this time, the concrete age varied between 294 and 315 days. Until the testing date, all specimens were kept in standard laboratory conditions (temperature of circa $20^{\circ} \mathrm{C}$, and relative humidity of approximately $50 \%$ ). In the end, three identical plain cylindrical concrete specimens were submitted to compressive tests. The mean values of the elastic modulus, according to [64], and compressive strength, according to [65], were $30.29 \mathrm{GPa}(\mathrm{CoV}=6.57 \%)$ and 33.49 $\mathrm{MPa}(\mathrm{CoV}=1.33 \%)$, respectively.

In ABAQUS software [40], two parameters are needed to describe the elastic behaviour of concrete: (i) the elastic modulus, and (ii) the Poisson's ratio. Equations (25) and (16) were used to define these parameters, in order to maintain coherence with the analytical model that was used to calibrate the numerical parameters.

Although the tensile behaviour of concrete is not important for the simulations conducted in the present study, it was defined aiming at widening the field of application of the model. The parameters required to define the tensile behaviour (the tensile strength, $f_{t}$, and the fracture energy, $G_{F}$ ) were obtained according to equations (35) and (36) [35]:

$$
\begin{aligned}
& f_{t}=1.4\left(\frac{f_{c 0}-8}{10}\right)^{2 / 3} \\
& G_{F}=\left(0.0469 d_{a}^{2}-0.5 d_{a}+26\right)\left(\frac{f_{c 0}}{10}\right)^{0.7}
\end{aligned}
$$

where $d_{\mathrm{a}}$ is the maximum aggregate size (assumed to be $12.5 \mathrm{~mm}$ in the present work). In the last equation, $f_{\mathrm{c} 0}$ is in MPa and $d_{\mathrm{a}}$ is in millimetres. In this way, $f_{t}$, obtained from equation (35), is in MPa and $G_{F}$, obtained from equation (36), is in $\mathrm{N} / \mathrm{m}$. 
Ribeiro, F.; Sena-Cruz, J.; Branco, F.; Júlio, E. (2019) "3D finite element model for hybrid FRP-confined concrete in compression using modified CDPM.” Engineering Structures, 190: 459-479.

DOI: 10.1016/j.engstruct.2019.04.027

The parameters used to define the non-linear compressive behaviour are already detailed in sections 2.2 and 3.4.

\section{COMPARISON OF FE MODEL PREDICTIONS WITH EXPERIMENTAL RESULTS}

The performance of the proposed CDPM is validated with the experimental results described in Section 3.1. In the work of Ribeiro et al. [3], it has already been proven that the analytical model here presented allows to accurately simulate both the dilation behaviour and the compressive stress-strain behaviour of all confined concrete specimens analysed. Since the material parameters for the modified CDPM were obtained from the referred to analytical model, predictions obtained with both models (analytical and numerical) are expected to have similar accuracy.

\subsection{Non-hybrid FRP-confined concrete}

In Figure 10 the evolution of $\Psi$ for the studied non-hybrid FRP-confined concrete combinations is presented. This parameter was computed according to equations (13) and (26) and it was introduced in CDPM in order to define the flow rule, taking into account the software limitations exposed in Section 2.2.2, i.e., negative values and values higher than $56^{\circ}$ were not considered. However, in the computation of $\Psi$, an infinite axial tensile strain was assumed to generate the input parameters, and then the lateral strain at failure of the different material combinations was assumed as the average of the corresponding experimental values.

In Figure 11 and Figure 12 the lateral strain-axial strain and the compressive stress-strain curves of nonhybrid FRP-confined concrete are presented. In the specimen designation, the last number (i.e., 1, 2 or 3) was used to make the distinction between the three identical specimens. Analytical and numerical curves are also plotted to allow the comparison with the corresponding experimental curves. A good agreement between theoretical and experimental results is observed.

As expected, all the numerical predictions obtained using the proposed modified CDPM are in close agreement with test results. Nevertheless, some differences are observed between analytical and numerical values. This is essentially due to two factors: (i) the allowed range of $\Psi$ have influence in the prediction of lateral strainaxial strain curves and (ii) the fact that stress-strain curves of FRP-confined concrete are interpolated from a reduced and fixed number of stress-strain curves for actively confined concrete (see Figure $\mathbf{1}$ (b)) leads to slope variations after the compressive stress-strain peak of plain concrete $\left(f_{\mathrm{c} 0}, \varepsilon_{\mathrm{c} 0}\right)$, represented in simulations with a red circle. 
Ribeiro, F.; Sena-Cruz, J.; Branco, F.; Júlio, E. (2019) "3D finite element model for hybrid FRP-confined concrete in compression using modified CDPM.” Engineering Structures, 190: 459-479.

DOI: 10.1016/j.engstruct.2019.04.027

As expected, the development of the compressive stress-strain curves follows approximately a bilinear law, where the slope of the first branch depends primarily on the properties of plain concrete. For this reason, the initial phase of the curves is similar for all combinations. The second branch depends on the confining pressure applied by the confining materials. The higher the elastic modulus of the jacket, the higher the slope of the second branch.

\subsection{Hybrid FRP-confined concrete}

All the $\Psi$-axial plastic strain curves used as input in the simulation of compressive behaviour of hybrid FRP-confined concrete are presented in Figure 13. It is possible to observe that, in hybrid jackets with non-linear tensile behaviour (see Table 4) there is an increase of $\Psi$ comparatively to cases in which premature failure of hybrid composites take place. This is due to the fact that tensile non-linear behaviour of jackets allows the rapid increase of the lateral strain of concrete, and, consequently the increase of $\Psi$. Again, it should be noted that in the computation of $\Psi$, an infinite tensile strain of hybrid FRP was assumed. However, the numerical simulations were interrupted when the mean lateral strain at the failure was reached.

Experimental lateral strain-axial strain and compressive stress-strain curves of hybrid FRP-confined are compared with corresponding analytical and numerical curves in Figure 14 to Figure 23. It is possible to observe that predictions are generally in reasonable agreement with test results.

It is also possible to observe that pseudo-ductile branches were predicted in 3 combinations, namely in 2G/1CHM/G, 1G/1CHM/1G, and 1B/1CHM/1B. This was expected since pseudo-ductile tensile responses (i.e., simultaneous multiple fractures of LS fibres and dispersed delamination) occurred in tensile tests of these combinations [63]. Although pseudo-ductile tensile response has occurred as well in 1C/1CHM/1C combination [63], this behaviour did not have a significant influence in the compressive results. This is due to the fact that (i) pseudo-ductile strain (defined as the extra strain between the final failure strain and the strain on the extrapolated initial slope line at the failure stress of the stress-strain diagram, as it is shown in Figure 9) of this combination is very low, and (ii) the hybrid FRP failure of the jacket occured sooner that it was expected [3]. In this way, the application in practice of this combination in confinement would lead to fragile failures.

The predicted tensile behaviour of $1 \mathrm{G} / 1 \mathrm{CHM} / 1 \mathrm{G} / 1 \mathrm{CHM} / 1 \mathrm{G}$ and $1 \mathrm{G} / 3 \mathrm{CHM} / 1 \mathrm{G}$ combinations indicates catastrophic delamination modes, meaning that there is an abrupt drop of stress after the failure of LS fibres. This leads to compressive behaviour of confined concrete very similar to the one that is obtained in non-hybrid FRPconfined concrete series, when these combinations are used as confining materials, as it is evident from experimental results. 
Ribeiro, F.; Sena-Cruz, J.; Branco, F.; Júlio, E. (2019) "3D finite element model for hybrid FRP-confined concrete in compression using modified CDPM.” Engineering Structures, 190: 459-479.

DOI: 10.1016/j.engstruct.2019.04.027

In the remaining cases, stress-strain curves development follows approximately a bilinear law, similarly to what was observed in non-hybrid FRP-confined concrete series. Please note that, in combination 1C/1B/1C, there are two outlier experimental results which were therefore ignored.

In all cases, analytical and numerical curves are almost coincident. This validates the strategy of CDPM modification that is proposed in the present work.

\section{CONCLUSIONS}

In the present study, the performance of a modified concrete damage plasticity model (CDPM) is validated against both experimental and analytical results. The modifications were implemented in both hardening and flow rules, turning them confining dependent. An analysis-oriented confinement model, based on the approach of Lim and Ozbakkaloglu [32, 33], was adopted to define the input parameters of the CDPM. Major conclusions drawn from this study are presented in the following paragraphs.

The need to contemplate friction forces in surface-to-surface contact between rigid steel plates and concrete was analysed. It was concluded that, if an analytical model that implicitly considers the frictions forces (such as the one considered in the present work) is used, to compute the input parameters of the numerical model, the end restrain does not need to be detailed.

It was observed that $K$ parameter (strength ratio of concrete under equal biaxial compression to triaxial compression) has a significant influence in the prediction of the peak stress of confined concrete. Then, a sensitivity analysis was carried out and it was concluded that assuming $K=0.68$ leads to residual errors in initial numerical predictions. For this reason, this value was assumed in the remaining part of the work.

The analytical model of Jalalvand et al. [4] was used to predict the input tensile parameters of hybrid FRP. In the $2 \mathrm{G} / 1 \mathrm{CHM} / \mathrm{G}, 1 \mathrm{G} / 1 \mathrm{CHM} / 1 \mathrm{G}, 1 \mathrm{~B} / 1 \mathrm{CHM} / 1 \mathrm{~B}$, and $1 \mathrm{C} / 1 \mathrm{CHM} / 1 \mathrm{C}$ combinations, plasticity was defined in order to take into account the pseudo-ductile tensile responses of the latter. In the remaining cases, a linear elastic behaviour was assumed. This approach has shown to provide accurate predictions for all FRP-confined circular concrete columns. As expected, pseudo-ductility was predicted in cases in which it was experimentally observed. Moreover, it should be highlighted that analytical and numerical curves are almost coincident.

As a final conclusion, taking into account what has been stated previously, it can be concluded that the developed 3D finite element model, using modified CDPM, can be adopted to accurately predict the compressive behaviour of hybrid FRP-confined concrete. 
Ribeiro, F.; Sena-Cruz, J.; Branco, F.; Júlio, E. (2019) "3D finite element model for hybrid FRP-confined concrete in compression using modified CDPM.” Engineering Structures, 190: 459-479.

DOI: 10.1016/j.engstruct.2019.04.027

It should be noted that while the presented study has demonstrated that hybrid FRP confinement can substantially enhance both the compressive strength and ductility of confined concrete in circular specimens, the latter cannot be taken as representative of large scale concrete columns. Although the obtained results regarding concrete behaviour are an important part of the overall input required for the structural analysis of concrete structures, further work needs to be conducted in large scale specimens before hybrid composites can be implemented in practice. Besides, the numerical model should be validated for different cross sections, steel (longitudinal and transverse) reinforcement ratios and configurations, and actions and loading types (monotonic or cyclic).

\section{Acknowledgments}

The authors wish to thank to FCT - Portuguese Foundation for Science and Technology and to the Doctoral Program Eco-Construction and Rehabilitation for supporting the $\mathrm{PhD}$ grant (PD/BD/52660/2014). Acknowledgements are extended to the following programs that partially supported the study herein presented: European Funds for Regional Development (FEDER) through the Operational Program for Competitiveness Factors (COMPETE), Operational Program for Competitiveness and Internationalization (POCI), and again FCT through both FRPLongDur POCI-01-0145-FEDER-016900 (FCT reference PTDC/ECM-EST/1282/2014) and POCI-01-0145-FEDER-007633 projects. Last but not least, the authors also acknowledge the support of both S\&P Clever Reinforcement Ibérica Lda and Dalla Betta Group Company.

\section{REFERENCES}

[1] Fahmy Mohamed FM, Ismail Ahmed M, Wu Z. Numerical Study on the Applicability of Design-Oriented Models of FRP-Confined Concrete for Predicting the Cyclic Response of Circular FRP-Jacketed RC Columns. Journal of Composites for Construction. 2017;21(5):04017017.

[2] Bank L. Composites for Construction - Structural Design with FRP Materials. John Wiley \& Sons, Inc. 2006. [3] Ribeiro F, Sena-Cruz J, Branco FG, Júlio E. Hybrid FRP jacketing for enhanced confinement of circular concrete columns in compression. Construction and Building Materials. 2018;184:681-704.

[4] Jalalvand M, Czél G, Wisnom MR. Damage analysis of pseudo-ductile thin-ply UD hybrid composites - A new analytical method. Composites: Part A. 2015;69:83-93.

[5] Grace NF, Abdel-Sayed G, Ragheb WF. Strengthening of Concrete Beams Using Innovative Ductile FiberReinforced Polymer Fabric. ACI Structural Journal. 2002;103(5)(99(5)):672-700.

[6] Grace NF, Ragheb WF, Abdel-Sayed G. Development and application of innovative triaxially braided ductile FRP fabric for strengthening concrete beams. Composite Structures 2004;64 521-30.

[7] Wu Z, Shao Y, Iwashita K, Sakamoto K. Strengthening of Preloaded RC Beams Using Hybrid Carbon Sheets. J Compos Constr. 2007;11:299-307.

[8] Attari N, Amziane S, Chemrouk M. Flexural strengthening of concrete beams using CFRP, GFRP and hybrid FRP sheets. Construction and Building Materials 2012;37 746-57.

[9] Hosny A, Shaheen H, Abdelrahman A, Elafandy T. Performance of reinforced concrete beams strengthened by hybrid FRP laminates. Cement \& Concrete Composites. 2006;28:906-13. 
[10] Hawileh RA, Rasheed HA, Abdalla JA, Al-Tamimi AK. Behavior of reinforced concrete beams strengthened with externally bonded hybrid fiber reinforced polymer systems. Materials and Design. 2014;53:972-82.

[11] Kang TH-K, Kim W, Ha S-S, Choi D-U. Hybrid Effects of Carbon-Glass FRP Sheets in Combination with or without Concrete Beams. International Journal of Concrete Structures and Materials Vol8, No1, pp27-41, March 2014 DOI 101007/s40069-013-0061-0. 2014.

[12] Zhang P, Zhu H, Wu G, Meng S, Wu Z. Flexural Performance of HFRP-RC Composite T-Beams with Different Interfaces. J Compos Constr, 04016101. 2016.

[13] Nikopour H, Nehdi M. Shear repair of RC beams using epoxy injection and hybrid external FRP. Materials and Structures. 2011;44:1865-187.

[14] Wu G, Wu ZS, Lu ZT, Ando YB. Structural Performance of Concrete Confined with Hybrid FRP Composites. Journal of reinforced plastics and composites. 2008;27(12).

[15] Luca AD, Nardone F, Matta F, Nanni A, Lignola GP, Prota A. Structural Evaluation of Full-Scale FRPConfined Reinforced Concrete Columns. J Compos Constr. 2011;15:112-23.

[16] Xu S, Li L, Guo Y. Study on experimental behavior of concrete circular column confined by HFRP under axial compression. Advanced Materials Research. 2012;450-451:491-4.

[17] Li L-J, Xu S-D, Zeng L, Guo Y-C. Study on mechanical behavior of circular concrete columns confined by HFRP under axial compressive load. Research and Applications in Structural Engineering, Mechanics and Computation - Zingoni (Ed) Taylor \& Francis Group, London, ISBN 978-1-138-00061-2. 2013.

[18] Li J, Samali B, Ye L, Bakoss S. Behaviour of concrete beam-column connections reinforced with hybrid FRP sheet. Composite Structures 2002;57:357-65.

[19] Li J, Bakoss SL, Samali B, Ye L. Reinforcement of concrete beam-column connections with hybrid FRP sheet. Composite Structures 1999;47:805-12.

[20] Attari N, Amziane S, Chemrouk M. Efficiency of Beam-Column Joint Strengthened by FRP Laminates. Advanced Composite Materials. 2010;19:171-83.

[21] Ispir M, Dalgic KD, Ilki A. Hybrid confinement of concrete through use of low and high rupture strain FRP. Composites Part B: Engineering. 2018;153:243-55.

[22] Hawileh RA, Abu-Obeidah A, Abdalla JA, Al-Tamimi A. Temperature effect on the mechanical properties of carbon, glass and carbon-glass FRP laminates. Construction and Building Materials 2015;75:342-8.

[23] Hawileh RA, Abdalla JA, Hasan SS, Ziyada MB, Abu-Obeidah A. Models for predicting elastic modulus and tensile strength of carbon, basalt and hybrid carbon-basalt FRP laminates at elevated temperatures. Construction and Building Materials. 2016;114:364-73.

[24] Swolfs Y, Gorbatikh L, Verpoest I. Fibre hybridisation in polymer composites: a review. Composites Part A: Applied Science and Manufacturing. 2014;67:181-200.

[25] Summerscales J, Short D. Carbon fibre and glass fibre hybrid reinforced plastics. Composites. 1978;9(3):15766.

[26] Czél G, Wisnom MR. Demonstration of pseudo-ductility in high performance glass/epoxy composites by hybridisation with thin-ply carbon prepreg. Composites: Part A: Applied Science and Manufacturing. 2013;52:2330 .

[27] Jalalvand M, Czél G, Wisnom MR. Numerical modelling of the damage modes in UD thin carbon/glass hybrid laminates. Composites Science and Technology. 2014;94:39-47.

[28] Jalalvand M, Czél G, Wisnom MR. Parametric study of failure mechanisms and optimal configurations of pseudo-ductile thin-ply UD hybrid composites. Composites: Part A. 2015; 74:123-31.

[29] Czél G, Jalalvand M, Wisnom MR. Design and characterisation of advanced pseudo-ductile unidirectional thin-ply carbon/epoxy-glass/epoxy hybrid composites. Composite Structures. 2016;143:362-70.

[30] Wisnom MR, Czél G, Swolfs Y, Jalalvand M, Gorbatikh L, Verpoest I. Hybrid effects in thin ply carbon/glass unidirectional laminates: Accurate experimental determination and prediction. Composites: Part A. 2016;88:1319.

[31] Yu H, Longana ML, Jalalvand M, Wisnom MR, Potter KD. Pseudo-ductility in intermingled carbon/glass hybrid composites with highly aligned discontinuous fibres. Composites: Part A 2015;73:35-44.

[32] Lim JC, Ozbakkaloglu T. Lateral Strain-to-Axial Strain Relationship of Confined Concrete. Journal of Structural Engineering. 2014;141(5).

[33] Lim JC, Ozbakkaloglu T. Unified Stress-Strain Model for FRP and Actively Confined Normal-Strength and High-Strength Concrete. Journal of Composites for Construction, ASCE, ISSN 1090-0268/04014072 (14). 2014.

[34] Yu T, Teng JG, Wong YL, Dong SL. Finite element modeling of confined concrete-II: Plastic-damage model. Engineering Structures. 2010;32(3):680-91.

[35] Lin G, Teng JG. Three-Dimensional Finite-Element Analysis of FRP-Confined Circular Concrete Columns under Eccentric Loading. Journal of Composites for Construction. 2017;21(4):04017003.

[36] Hany NF, Hantouche EG, Harajli MH. Finite element modeling of FRP-confined concrete using modified concrete damaged plasticity. Engineering Structures. 2016;125:1-14. 
Ribeiro, F.; Sena-Cruz, J.; Branco, F.; Júlio, E. (2019) "3D finite element model for hybrid FRP-confined concrete in compression using modified CDPM.” Engineering Structures, 190: 459-479.

DOI: 10.1016/j.engstruct.2019.04.027

[37] Ozbakkaloglu T, Gholampour A, Lim JC. Damage-Plasticity Model for FRP-Confined Normal-Strength and High-Strength Concrete. Journal of Composites for Construction. 2016;20(6):04016053.

[38] Lubliner J, Oliver J, Oller S, Oñate E. A plastic-damage model for concrete. International Journal of Solids and Structures. 1989;25(3):299-326.

[39] Lee J, Fenves GL. Plastic-Damage Model for Cyclic Loading of Concrete Structures. Journal of Engineering Mechanics. 1998;124(8):892-900.

[40] ABAQUS version 6.14 [Computer software]. Dassault Systèmes, Waltham, MA.

[41] Chi Y, Yu M, Huang L, Xu L. Finite element modeling of steel-polypropylene hybrid fiber reinforced concrete using modified concrete damaged plasticity. Engineering Structures. 2017;148:23-35.

[42] Lim JC, Ozbakkaloglu T. Stress-strain model for normal- and light-weight concretes under uniaxial and triaxial compression. Construction and Building Materials. 2014;71(Supplement C):492-509.

[43] Candappa DC, Sanjayan JG, Setunge S. Complete Triaxial Stress-Strain Curves of High-Strength Concrete. Journal of Materials in Civil Engineering. 2001;13(3):209-32.

[44] Popovics S. A Numerical Approach to the Complete Stress-Strain Curves for Concrete. Cement and Concrete Research. 1973;3(5):583-99.

[45] Domingo JC, Kuang-Han C. Stress-Strain Relationship for Plain Concrete in Compression. Journal Proceedings.82(6).

[46] Duarte APC, Silva BA, Silvestre N, de Brito J, Júlio E, Castro JM. Finite element modelling of short steel tubes filled with rubberized concrete. Composite Structures. 2016;150:28-40.

[47] Tysmans T, Wozniak M, Remy O, Vantomme J. Finite element modelling of the biaxial behaviour of highperformance fibre-reinforced cement composites (HPFRCC) using Concrete Damaged Plasticity. Finite Elements in Analysis and Design. 2015;100:47-53.

[48] Kmiecik P, KamiŃSki M. Modelling of reinforced concrete structures and composite structures with concrete strength degradation taken into consideration. Archives of Civil and Mechanical Engineering. 2011;11(3):623-36. [49] Jankowiak T, Łodygowski T. Identification of parameters of concrete damage plasticity constitutive model. Foundations of Civil and Environmental Engineering. 2005;6:53-69.

[50] Behnam H, Kuang JS, Samali B. Parametric finite element analysis of RC wide beam-column connections. Computers \& Structures. 2018;205:28-44.

[51] Nzabonimpa JD, Hong W-K. Structural performance of detachable precast composite column joints with mechanical metal plates. Engineering Structures. 2018;160:366-82.

[52] Singh M, Sheikh AH, Mohamed Ali MS, Visintin P, Griffith MC. Experimental and numerical study of the flexural behaviour of ultra-high performance fibre reinforced concrete beams. Construction and Building Materials. 2017;138:12-25.

[53] ASTM. D 3379 - 75 - Standard Test Method for Tensile Strength and Young's Modulus for High-Modulus Single-Filament Materials. 1989.

[54] ISO. 527-5 Plastics - Determination of tensile properties; Part 5: Test conditions for unidirectional fibrereinforced plastic composites. EUROPEAN COMMITTEE FOR STANDARDIZATION. 2009.

[55] S\&P. Technical Data Sheet S\&P Resin 55. 2015.

[56] CNR-DT200. Guide for the Design and Construction of Externally Bonded FRP Systems for Strengthening Existing Structures. Advisory Committee on Techincal Recommendations for Construction, National Research Council, Rome, Italy. 2013.

[57] Kotsovos MD. Finite-Element Modelling of Structural Concrete: Short-Term Static and Dynamic Loading Conditions. 1st ed: CRC Press; 2017.

[58] BSI. BS 5975:2008+A1:2011 - Code of practice for temporary works procedures and the permissible stress design of falsework.2008.

[59] Teng JG, Xiao QG, Yu T, Lam L. Three-dimensional finite element analysis of reinforced concrete columns with FRP and/or steel confinement. Engineering Structures. 2015;97:15-28.

[60] Kupfer H, Hilsdorf HK, Rusch H. Behavior of concrete under biaxial stresses. ACI Journal. 1969(66-52).

[61] Papanikolaou VK, Kappos AJ. Confinement-sensitive plasticity constitutive model for concrete in triaxial compression. International Journal of Solids and Structures. 2007;44(21):7021-48.

[62] Tao Z, Wang Z-B, Yu Q. Finite element modelling of concrete-filled steel stub columns under axial compression. Journal of Constructional Steel Research. 2013;89:121-31.

[63] Ribeiro F, Sena-Cruz J, Branco FG, Júlio E. Hybrid effect and pseudo-ductile behaviour of unidirectional interlayer hybrid FRP composites for civil engineering applications. Construction and Building Materials. 2018;171:871-90.

[64] CEN. EN 12390-13:2013 - Testing hardened concrete - Part 13: Determination of secant modulus of elasticity in compression. 2013.

[65] CEN. EN 12390-3:2009 - Testing hardened concrete - Part 3: Compressive strength of test specimens. 2009. 
Ribeiro, F.; Sena-Cruz, J.; Branco, F.; Júlio, E. (2019) "3D finite element model for hybrid FRP-confined concrete in compression using modified CDPM.” Engineering Structures, 190: 459-479.

DOI: 10.1016/j.engstruct.2019.04.027

\section{Nomenclature}

$\bar{I}_{1}$ first effective stress invariant

$\bar{J}_{2}$ second effective deviatoric stress invariant

$\bar{\sigma}_{\min }$ minimum principal effective stress

$f_{\mathrm{c} 0}$ peak stress of the unconfined concrete

$f_{\mathrm{b}}$ concrete strength under equal biaxial compression

$\bar{\sigma}_{c n}$ effective compressive cohesion stress

$\bar{\sigma}_{t n}$ effective tensile cohesion stress

$\tilde{\varepsilon}_{p, c}$ compressive plastic strain

$\tilde{\varepsilon}_{p, t}$ tensile plastic strain

$K$ strength ratio of concrete under equal biaxial compression to triaxial compression

$f_{c}$ compressive stress

$\bar{f}_{c}$ effective principal compressive stress

$f_{l}$ confining pressure

$f_{l, 1}$ confining pressure in direction 1

$f_{l, 2}$ confining pressure in direction 2

$\bar{f}_{l, 1}$ effective principal lateral stress in direction 1

$\bar{f}_{l, 2}$ effective principal lateral stresses in direction 2

$f_{i j}$ stress tensor

$\bar{f}_{i j}$ effective stress tensor

$d_{i j}$ damage tensor

$\varepsilon_{i j}$ strain tensor

$\varepsilon_{i j}^{p}$ plastic strain tensor

$D_{i j k l}^{e}$ initial elasticity matrix

$f_{c c}^{*}$ peak stress of actively confined concrete

$d \varepsilon_{i j}^{p}$ flow rule

$G$ Drucker-Prager hyperbolic function

$\sigma_{\text {to }}$ uniaxial tensile stress at failure 
Ribeiro, F.; Sena-Cruz, J.; Branco, F.; Júlio, E. (2019) “3D finite element model for hybrid FRP-confined concrete in compression using modified CDPM.” Engineering Structures, 190: 459-479.

DOI: 10.1016/j.engstruct.2019.04.027

$\ni$ eccentricity parameter

$\Psi$ plastic dilation angle

$\varepsilon_{c, p}$ axial plastic strain

$\varepsilon_{l, p}$ lateral plastic strain

$v_{\mathrm{i}}$ initial Poisson's ratio of concrete

$f_{c c}^{*}$ peak stress of actively confined concrete

$\varepsilon_{c}$ axial strain

$\varepsilon_{c c}^{*}$ peak strain of actively confined concrete

$r$ concrete brittleness

$f_{\mathrm{c}, \text { res }}$ residual stress

$\varepsilon_{\mathrm{c}, \mathrm{i}}$ axial strain corresponding to the inflection point of the descending branch of stress-strain curve

$E_{\mathrm{c}}$ is the elastic modulus of plain concrete

$\varepsilon_{\mathrm{c} 0}$ axial strain at the peak stress of the unconfined concrete

$n$ curve shape parameter

$t_{\mathrm{L}}$ half thickness of the LS layers

$t_{\mathrm{H}}$ half thickness of the HS layers

$\sigma @ L F$ stress at which the first crack in the LS material occurs

$\sigma @ d e l$ stress at which delamination starts

$\sigma @ H F$ stress at which the HS material fails

$S_{\mathrm{L}}$ reference strength of the LS material

$\alpha$ modulus ratios of the LS to HS fibres

$\beta$ thickness ratios of the LS to HS fibres

$G_{I I C}$ mode II interlaminar fracture toughness of the interface between LS layers and HS layers

$E_{\mathrm{H}}$ elastic modulus of the HS fibres

$m_{H}$ Weibull strength distribution modulus of the HS fibres

$V$ volume of the specimen

$\sigma_{\text {hybrid }}$ tensile strength of hybrid composites

$E_{\text {hybrid }}$ elastic modulus of hybrid composites

$\varepsilon_{t, F R P}^{p l}$ tensile plastic strain of hybrid composites 
Ribeiro, F.; Sena-Cruz, J.; Branco, F.; Júlio, E. (2019) "3D finite element model for hybrid FRP-confined concrete in compression using modified CDPM.” Engineering Structures, 190: 459-479.

DOI: 10.1016/j.engstruct.2019.04.027

$\varepsilon_{t, \text { hybrid }}$ total tensile strain of hybrid composites

$f_{t}$ tensile strength

$G_{F}$ fracture energy

$d_{a}$ maximum aggregate size 
Ribeiro, F.; Sena-Cruz, J.; Branco, F.; Júlio, E. (2019) “3D finite element model for hybrid FRP-confined concrete in compression using modified CDPM.” Engineering Structures, 190: 459-479.

DOI: 10.1016/j.engstruct.2019.04.027

\section{List of Tables}

Table 1 - Properties of the dry fabrics, fibres and cured composite materials determined experimentally.

Table 2 - Summary of tested compression specimens.

Table 3 - Summary of different damage modes in function of stress level (adapted from [12])

Table 4 - Tensile properties of hybrid FRP composites [46]. 
Ribeiro, F.; Sena-Cruz, J.; Branco, F.; Júlio, E. (2019) “3D finite element model for hybrid FRP-confined concrete in compression using modified CDPM." Engineering Structures, 190: 459-479.

DOI: 10.1016/j.engstruct.2019.04.027

Table 1 - Properties of the dry fabrics, fibres and cured composite materials determined experimentally.

\begin{tabular}{|c|c|c|c|c|c|c|c|c|c|c|c|}
\hline \multirow[t]{2}{*}{ Material ID } & \multicolumn{3}{|c|}{$\begin{array}{l}\text { Properties of the dry fabric, as } \\
\text { reporter by the manufacturer }\end{array}$} & \multicolumn{5}{|c|}{ Properties of the fibres (tested according to ASTM D3379) } & \multicolumn{3}{|c|}{ Properties of 1 ply composites [63]* } \\
\hline & $\begin{array}{l}\text { Density } \\
{\left[\mathrm{g} / \mathrm{m}^{3}\right]}\end{array}$ & $\begin{array}{l}\text { Areal } \\
\text { mass } \\
{\left[\mathrm{g} / \mathrm{m}^{2}\right]}\end{array}$ & $\begin{array}{l}\text { Fibre layer } \\
\text { thickness } \\
\text { [mm/layer] }\end{array}$ & $\begin{array}{c}\text { N. of } \\
\text { samples }\end{array}$ & $\begin{array}{c}\text { Fibre } \\
\text { diameter } \\
{[\mu \mathrm{m}]} \\
(\mathrm{CoV}[\%])\end{array}$ & $\begin{array}{c}\text { Elastic } \\
\text { modulus } \\
{[\mathrm{GPa}]} \\
(\mathrm{CoV}[\%])\end{array}$ & $\begin{array}{c}\text { Tensile } \\
\text { strength } \\
\text { [MPa] } \\
(\mathrm{CoV}[\%])\end{array}$ & $\begin{array}{c}\text { Strain at } \\
\text { the failure } \\
{[\%]} \\
(\mathrm{CoV}[\%])\end{array}$ & $\begin{array}{c}\text { Elastic } \\
\text { modulus } \\
{[\mathrm{GPa}]} \\
(\mathrm{CoV}[\%])\end{array}$ & $\begin{array}{c}\text { Tensile } \\
\text { strength } \\
\text { [MPa] } \\
(\mathrm{CoV}[\%])\end{array}$ & $\begin{array}{c}\text { Strain at } \\
\text { the strain } \\
{[\%]} \\
(\mathrm{CoV}[\%])\end{array}$ \\
\hline Basalt (B) & 2.67 & 420 & 0.157 & 50 & $\begin{array}{l}18.14 \\
(3.56)\end{array}$ & $\begin{array}{l}61.41 \\
(31.14)\end{array}$ & $\begin{array}{l}1886.70 \\
(40.79)\end{array}$ & $\begin{array}{c}3.10 \\
(27.73)\end{array}$ & $\begin{array}{l}102.5 \\
(15.46)\end{array}$ & $\begin{array}{l}2244.2 \\
(20.17)\end{array}$ & $\begin{array}{c}2.46 \\
(10.61)\end{array}$ \\
\hline E-glass (G) & 2.60 & 400 & 0.154 & 50 & $\begin{array}{c}14.98 \\
(16.25)\end{array}$ & $\begin{array}{c}76.92 \\
(27.97)\end{array}$ & $\begin{array}{l}2662.06 \\
(33.88)\end{array}$ & $\begin{array}{c}3.72 \\
(20.45)\end{array}$ & $\begin{array}{l}81.6 \\
(7.39)\end{array}$ & $\begin{array}{l}1671.2 \\
(8.59)\end{array}$ & $\begin{array}{c}2.31 \\
(3.78)\end{array}$ \\
\hline ST carbon $(\mathrm{C})$ & 1.79 & 400 & 0.223 & 36 & $\begin{array}{l}7.88 \\
(5.15)\end{array}$ & $\begin{array}{l}213.95 \\
(43.36)\end{array}$ & $\begin{array}{l}3920.67 \\
(39.37)\end{array}$ & $\begin{array}{c}1.38 \\
(17.37)\end{array}$ & $\begin{array}{l}231.3 \\
(12.50)\end{array}$ & $\begin{array}{l}2565.9 \\
(10.18)\end{array}$ & $\begin{array}{l}1.09 \\
(8.81)\end{array}$ \\
\hline $\mathrm{HM}$ carbon $(\mathrm{CHM})$ & 2.10 & 400 & 0.190 & 26 & $\begin{array}{l}11.03 \\
(6.66)\end{array}$ & $\begin{array}{l}558.07 \\
(24.67)\end{array}$ & $\begin{array}{c}2934.24 \\
(19.16)\end{array}$ & $\begin{array}{c}0.53 \\
(18.99)\end{array}$ & $\begin{array}{c}624.1 \\
(11.13)\end{array}$ & $\begin{array}{l}1749.4 \\
(24.39)\end{array}$ & $\begin{array}{c}0.27 \\
(19.61)\end{array}$ \\
\hline
\end{tabular}

Note: *The tensile properties were computed considering only the thickness of the dry fabrics, according the recommendation suggested in the guidelines [31]. 
Ribeiro, F.; Sena-Cruz, J.; Branco, F.; Júlio, E. (2019) "3D finite element model for hybrid FRP-confined concrete in compression using modified CDPM.” Engineering Structures, 190: 459-479.

DOI: 10.1016/j.engstruct.2019.04.027

Table 2 - Summary of tested compression specimens.

\begin{tabular}{|c|c|c|c|c|}
\hline $\begin{array}{c}\text { Jacketing } \\
\text { type }\end{array}$ & Designation & $\begin{array}{l}\text { Stacking } \\
\text { sequence }\end{array}$ & Jacketing material combinations & $\begin{array}{c}\text { Number of tests per type } \\
\text { of stacking sequence }\end{array}$ \\
\hline Non-hybrid & -- & & $\mathrm{G}, \mathrm{B}, \mathrm{CHM}, \mathrm{C}$ & 12 \\
\hline \multirow[t]{5}{*}{ Hybrid } & 1LS/1HS/1LS & & $\mathrm{C} / \mathrm{B}, \mathrm{CHM} / \mathrm{B}, \mathrm{CHM} / \mathrm{C}, \mathrm{C} / \mathrm{G}, \mathrm{CHM} / \mathrm{G}$ & 15 \\
\hline & 1HS/3LS/1HS & & $\mathrm{C} / \mathrm{G}, \mathrm{CHM} / \mathrm{G}$ & 6 \\
\hline & 1HS/1LS/1HS/1LS/1HS & & $\mathrm{C} / \mathrm{G}, \mathrm{CHM} / \mathrm{G}$ & 6 \\
\hline & 1HS/1LS/1HS & & $\mathrm{C} / \mathrm{B}, \mathrm{CHM} / \mathrm{B}, \mathrm{CHM} / \mathrm{C}, \mathrm{C} / \mathrm{G}, \mathrm{CHM} / \mathrm{G}$ & 15 \\
\hline & $2 \mathrm{HS} / 1 \mathrm{LS} / 2 \mathrm{HS}$ & & $\mathrm{C} / \mathrm{G}, \mathrm{CHM} / \mathrm{G}$ & 6 \\
\hline
\end{tabular}


Ribeiro, F.; Sena-Cruz, J.; Branco, F.; Júlio, E. (2019) “3D finite element model for hybrid FRP-confined concrete in compression using modified CDPM.” Engineering Structures, 190: 459-479.

DOI: 10.1016/j.engstruct.2019.04.027

Table 3 - Summary of different damage modes in function of stress level (adapted from [28]).

\begin{tabular}{|c|c|}
\hline Damage mode & Stress level \\
\hline \multirow[t]{2}{*}{ Premature failure } & $\sigma @ H F \leq \sigma @ L F \leq \sigma @ d e l$ \\
\hline & $\sigma @ H F \leq \sigma @ d e l \leq \sigma @ L F$ \\
\hline \multirow[t]{2}{*}{ Catastrophic delamination } & $\sigma @ d e l \leq \sigma @ H F \leq \sigma @ L F$ \\
\hline & $\sigma @ d e l \leq \sigma @ L F \leq \sigma @ H F$ \\
\hline Fragmentation & $\sigma @ L F \leq \sigma @ H F \leq \sigma @ d e l$ \\
\hline Fragmentation \& dispersed delamination & $\sigma @ L F \leq \sigma @ d e l \leq \sigma @ H F$ \\
\hline
\end{tabular}


Ribeiro, F.; Sena-Cruz, J.; Branco, F.; Júlio, E. (2019) “3D finite element model for hybrid FRP-confined concrete in compression using modified CDPM.” Engineering Structures, 190: 459-479.

DOI: 10.1016/j.engstruct.2019.04.027

Table 4 - Tensile properties of hybrid FRP composites [63].

\begin{tabular}{|c|c|c|c|c|c|c|c|c|c|c|c|c|c|c|}
\hline \multirow[t]{4}{*}{ Combination } & \multirow[t]{4}{*}{ Series ID } & \multirow{4}{*}{$\begin{array}{c}\text { Volume of LS } \\
\text { fibres [\%] }\end{array}$} & \multirow{4}{*}{$\begin{array}{c}\text { Elastic modulus } \\
\text { [GPa] }\end{array}$} & \multirow{4}{*}{$\begin{array}{c}\mathrm{t}_{\mathrm{FRP}} \\
{[\mathrm{mm}]}\end{array}$} & \multicolumn{10}{|c|}{ Tensile stress-strain analytical curve } \\
\hline & & & & & \multicolumn{2}{|c|}{ Point 1} & \multicolumn{2}{|c|}{ Point 2} & \multicolumn{2}{|c|}{ Point 3} & \multicolumn{2}{|c|}{ Point 3} & \multicolumn{2}{|c|}{ Point 5} \\
\hline & & & & & Strain & Stress & Strain & Stress & Strain & Stress & Strain & Stress & Strain & Stress \\
\hline & & & & & $(\%)$ & $(\mathrm{MPa})$ & $(\%)$ & $(\mathrm{MPa})$ & $(\%)$ & (MPa) & $(\%)$ & $(\mathrm{MPa})$ & $(\%)$ & (MPa) \\
\hline \multirow[t]{2}{*}{$\mathrm{C} / \mathrm{B}$} & $1 \mathrm{C} / 1 \mathrm{~B} / 1 \mathrm{C}$ & 74.0 & 218.4 & 0.60 & 0.00 & 0.0 & 0.99 & 1957.9 & -- & -- & -- & -- & -- & -- \\
\hline & $1 \mathrm{~B} / 1 \mathrm{C} / 1 \mathrm{~B}$ & 41.5 & 152.5 & 0.54 & 0.00 & 0.0 & 1.28 & 1996.6 & -- & -- & -- & -- & -- & -- \\
\hline \multirow[t]{2}{*}{ CHM/B } & 1CHM/1B/1CHM & 70.8 & 474.1 & 0.54 & 0.00 & 0.0 & 0.24 & 1131.8 & -- & -- & -- & -- & -- & -- \\
\hline & 1B/1CHM/1B & 37.7 & 297.4 & 0.50 & 0.00 & 0.0 & 0.36 & 1077.0 & 1.17 & 1077.0 & 1.73 & 1106.0 & 2.03 & 1152.3 \\
\hline \multirow[t]{2}{*}{$\mathrm{CHM} / \mathrm{C}$} & $1 \mathrm{CHM} / 1 \mathrm{C} / 1 \mathrm{CHM}$ & 63.0 & 489.6 & 0.60 & 0.00 & 0.0 & 0.27 & 1292.7 & -- & -- & -- & -- & -- & -- \\
\hline & $1 \mathrm{C} / 1 \mathrm{CHM} / 1 \mathrm{C}$ & 29.5 & 368.8 & 0.64 & 0.00 & 0.0 & 0.39 & 1359.8 & 0.66 & 1359.8 & 0.95 & 1544.3 & 0.94 & 1544.9 \\
\hline \multirow[t]{5}{*}{$\mathrm{C} / \mathrm{G}$} & $1 \mathrm{C} / 1 \mathrm{G} / 1 \mathrm{C}$ & 74.3 & 201.7 & 0.60 & 0.00 & 0.0 & 1.04 & 2005.5 & -- & -- & -- & -- & -- & -- \\
\hline & $1 \mathrm{G} / 3 \mathrm{C} / 1 \mathrm{G}$ & 68.5 & 202.4 & 0.98 & 0.00 & 0.0 & 1.08 & 1988.4 & -- & -- & -- & -- & -- & -- \\
\hline & $1 \mathrm{G} / 1 \mathrm{C} / 1 \mathrm{G} / 1 \mathrm{C} / 1 \mathrm{G}$ & 49.1 & 148.9 & 0.91 & 0.00 & 0.0 & 1.19 & 1830.5 & -- & -- & -- & -- & -- & -- \\
\hline & $1 \mathrm{G} / 1 \mathrm{C} / 1 \mathrm{G}$ & 42.0 & 146.7 & 0.53 & 0.00 & 0.0 & 1.27 & 1820.3 & -- & -- & -- & -- & -- & -- \\
\hline & $2 \mathrm{G} / 1 \mathrm{C} / 2 \mathrm{G}$ & 26.6 & 110.8 & 0.84 & 0.00 & 0.0 & 1.18 & 1420.3 & -- & -- & -- & -- & -- & -- \\
\hline \multirow[t]{5}{*}{$\mathrm{CHM} / \mathrm{G}$} & $1 \mathrm{CHM} / 1 \mathrm{G} / 1 \mathrm{CHM}$ & 71.2 & 454.5 & 0.53 & 0.00 & 0.0 & 0.25 & 1201.9 & -- & -- & -- & -- & -- & -- \\
\hline & $1 \mathrm{G} / 3 \mathrm{CHM} / 1 \mathrm{G}$ & 64.9 & 439.2 & 0.88 & 0.00 & 0.0 & 0.23 & 997.7 & 0.23 & 451.5 & 1.58 & 451.5 & 1.91 & 483.5 \\
\hline & $1 \mathrm{G} / 1 \mathrm{CHM} / 1 \mathrm{G} / 1 \mathrm{CHM} / 1 \mathrm{G}$ & 45.1 & 318.7 & 0.84 & 0.00 & 0.0 & 0.35 & 1142.5 & 0.35 & 599.9 & 1.34 & 599.9 & 1.88 & 745.8 \\
\hline & $1 \mathrm{G} / 1 \mathrm{CHM} / 1 \mathrm{G}$ & 38.2 & 252.0 & 0.50 & 0.00 & 0.0 & 0.30 & 846.2 & 1.14 & 846.2 & 1.68 & 846.9 & 1.91 & 852.4 \\
\hline & $2 \mathrm{G} / 1 \mathrm{CHM} / 2 \mathrm{G}$ & 23.6 & 214.3 & 0.81 & 0.00 & 0.0 & 0.33 & 691.3 & 0.81 & 691.3 & 1.29 & 802.1 & 1.86 & 1028.7 \\
\hline
\end{tabular}


Ribeiro, F.; Sena-Cruz, J.; Branco, F.; Júlio, E. (2019) “3D finite element model for hybrid FRP-confined concrete in compression using modified CDPM.” Engineering Structures, 190: 459-479.

DOI: 10.1016/j.engstruct.2019.04.027

\section{List of Figures}

Figure 1 - Numerical versus analytical stress-strain curves of actively-confined concrete: (a) original and (b) modified CDPM.

Figure 2 - Numerical versus analytical lateral strain-axial strain curves: (a) considering a constant dilation angle, and (b) considering variation of the dilation angle in function of level of confining pressure.

Figure 3 - Plastic dilation angle of actively-confined concrete in function of axial plastic strain for several levels of confining pressure.

Figure 5 - Distribution of lateral displacement of plain concrete at the peak stress in one of the two lateral principal stress directions: (a) considering frictional forces and (b) without considering frictional forces.

Figure 6 - Evaluation of the effect of end restrains contemplation in the compressive stress-strain curve of plain concrete.

Figure 7 - Influence of $K$ the yield surface of CDPM: (a) principal stress space and (b) deviatoric plane $\left(\left(f_{\mathrm{c}}+f_{1,1}+f_{1,2}\right) / 3=100\right)$

Figure 8 - Peak stress of actively confined concrete in function of $f_{1}$ and $K$. 40

Figure 9 - Tensile nonlinear behaviour of hybrid FRP.

Figure 10 - Plastic dilation angle of non-hybrid FRP-confined concrete in function of axial plastic strain. ..... 42

Figure 11 - Lateral strain-axial strain curves: (a) basalt; (b) glass; (c) ST carbon and (d) HM carbon composite confined concrete.

Figure 12 - Axial stress-strain curves: (a) basalt; (b) glass; (c) ST carbon and (d) HM carbon composite confined concrete

Figure 13 - Plastic dilation angle of hybrid FRP-confined concrete in function of axial plastic strain: (a) HM carbon/glass; (b) ST carbon/glass; (c) HM carbon/basalt; (d) ST carbon/basalt and (e) HM carbon/ST carbon composites

Figure 14 - Lateral strain-axial strain curves of CHM/G combinations: experimental versus predicted values.46

Figure 15 - Lateral strain-axial strain curves of $\mathrm{C} / \mathrm{G}$ combinations: experimental versus predicted values.

Figure 16 - Lateral strain-axial strain curves of CHM/B combinations: experimental versus predicted values.48

Figure 17 - Lateral strain-axial strain curves of C/B combinations: experimental versus predicted values. 
Ribeiro, F.; Sena-Cruz, J.; Branco, F.; Júlio, E. (2019) “3D finite element model for hybrid FRP-confined concrete in compression using modified CDPM.” Engineering Structures, 190: 459-479.

DOI: 10.1016/j.engstruct.2019.04.027

Figure 18 - Lateral strain-axial strain curves of CHM/C combinations: experimental versus predicted values.50

Figure 19 - Stress-strain curves of CHM/G combinations: experimental versus predicted values. .51

Figure 20 - Stress-strain curves of $\mathrm{C} / \mathrm{G}$ combinations: experimental versus predicted values. .52

Figure 21 - Stress-strain curves of CHM/B combinations: experimental versus predicted values. .53

Figure 22 - Stress-strain curves of C/B combinations: experimental versus predicted values. 54

Figure 23 - Stress-strain curves of CHM/C combinations: experimental versus predicted values. 55 
Ribeiro, F.; Sena-Cruz, J.; Branco, F.; Júlio, E. (2019) “3D finite element model for hybrid FRP-confined concrete in compression using modified CDPM.” Engineering Structures, 190: 459-479.

DOI: 10.1016/j.engstruct.2019.04.027

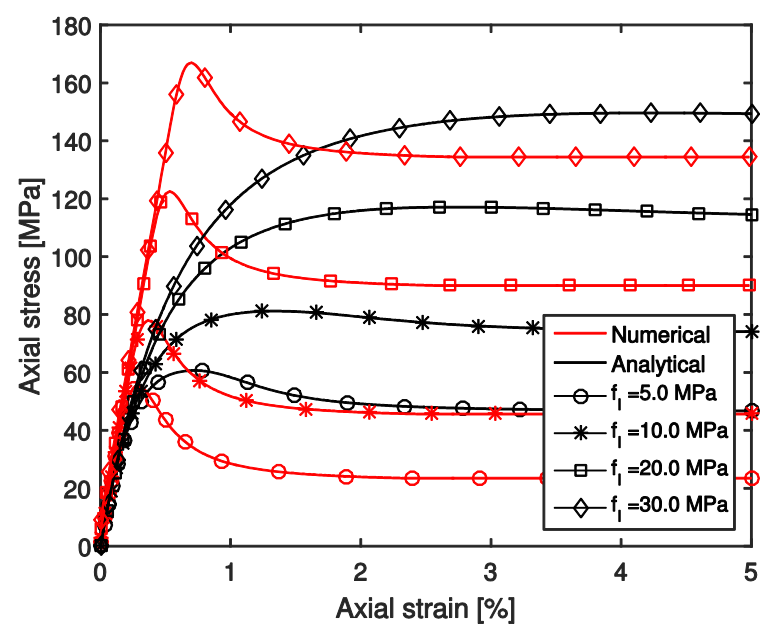

(a)

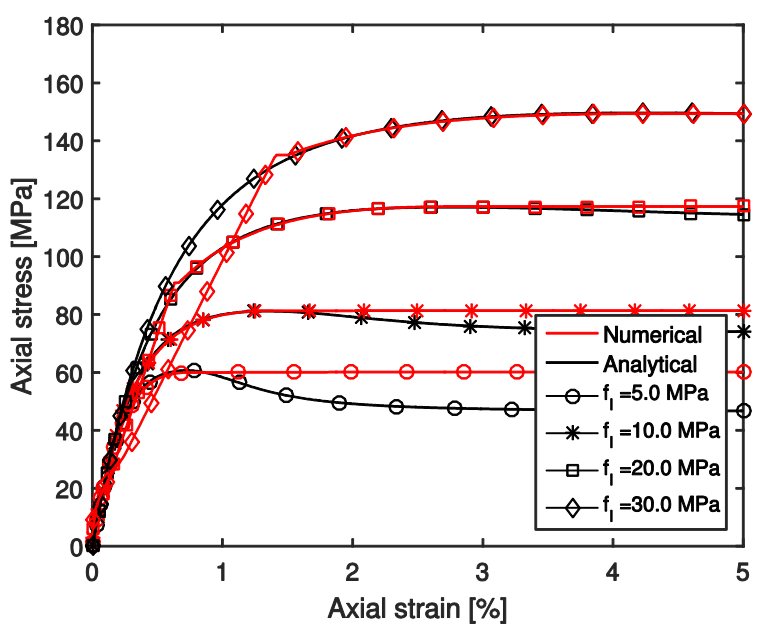

(b)

Figure 1 - Numerical versus analytical stress-strain curves of actively-confined concrete: (a) original and (b) modified CDPM. 
Ribeiro, F.; Sena-Cruz, J.; Branco, F.; Júlio, E. (2019) “3D finite element model for hybrid FRP-confined concrete in compression using modified CDPM.” Engineering Structures, 190: 459-479.

DOI: 10.1016/j.engstruct.2019.04.027

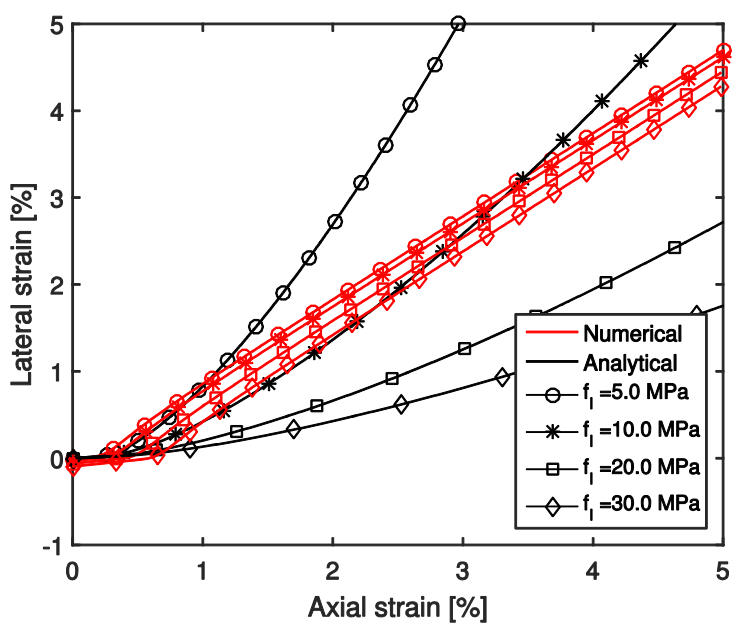

(a)

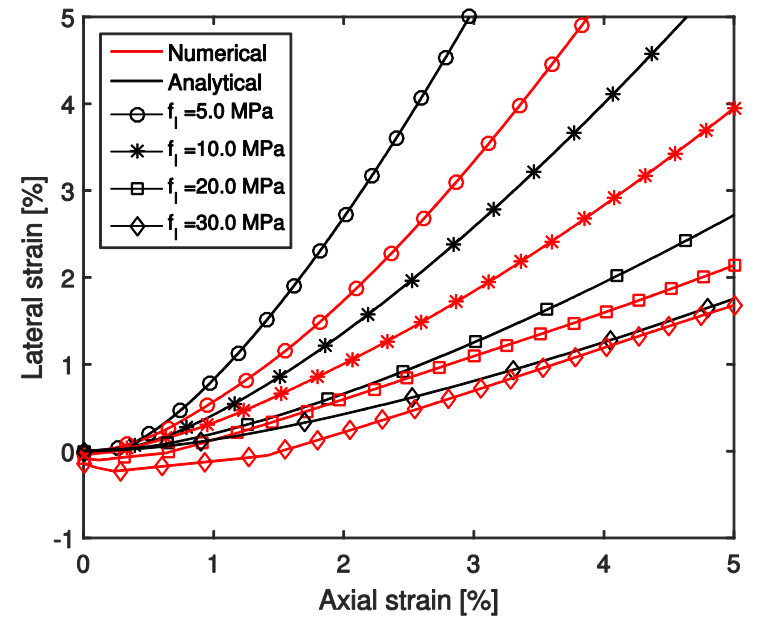

(b)

Figure 2 - Numerical versus analytical lateral strain-axial strain curves: (a) considering a constant dilation angle, and (b) considering variation of the dilation angle in function of level of confining pressure. 
Ribeiro, F.; Sena-Cruz, J.; Branco, F.; Júlio, E. (2019) “3D finite element model for hybrid FRP-confined concrete in compression using modified CDPM.” Engineering Structures, 190: 459-479.

DOI: 10.1016/j.engstruct.2019.04.027

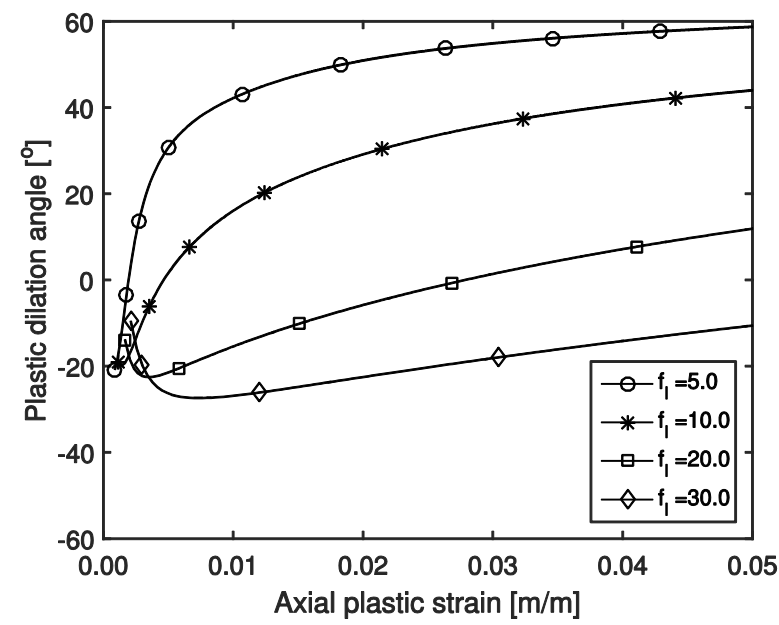

Figure 3 - Plastic dilation angle of actively-confined concrete in function of axial plastic strain for several levels of confining pressure. 
Ribeiro, F.; Sena-Cruz, J.; Branco, F.; Júlio, E. (2019) “3D finite element model for hybrid FRP-confined concrete in compression using modified CDPM.” Engineering Structures, 190: 459-479.

DOI: 10.1016/j.engstruct.2019.04.027

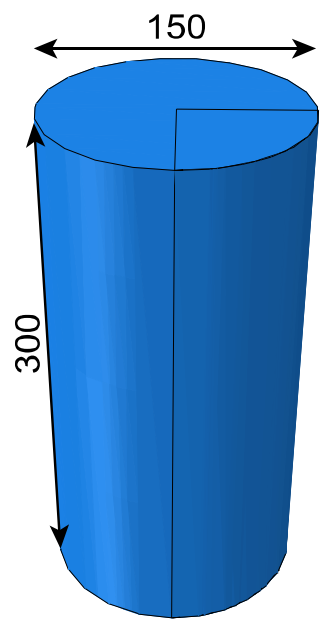

(a)

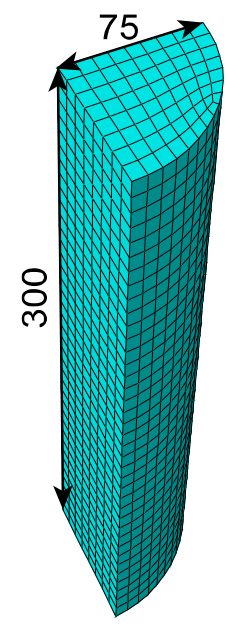

(b)

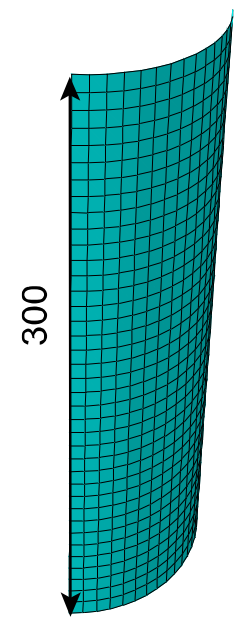

(c)

Figure 4 - Geometric representation of FE model: (a) full specimen, (b) mesh of 1/4 concrete specimen, and (c) mesh of 1/4 FRP jacket (dimensions in mm). 
Ribeiro, F.; Sena-Cruz, J.; Branco, F.; Júlio, E. (2019) "3D finite element model for hybrid FRP-confined concrete in compression using modified CDPM.” Engineering Structures, 190: 459-479.

DOI: 10.1016/j.engstruct.2019.04.027

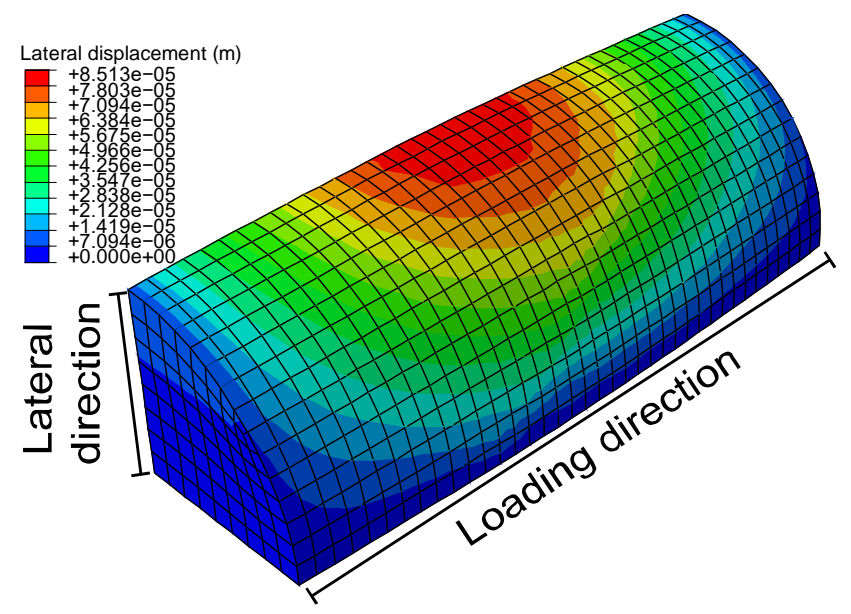

(a)

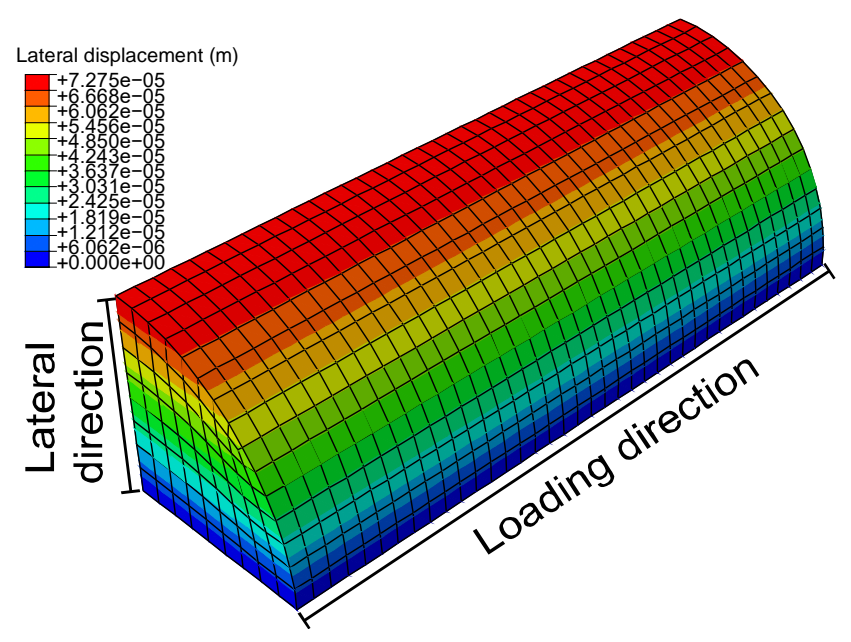

(b)

Figure 5 - Distribution of lateral displacement of plain concrete at the peak stress in one of the two lateral principal stress directions: (a) considering frictional forces and (b) without considering frictional forces. 
Ribeiro, F.; Sena-Cruz, J.; Branco, F.; Júlio, E. (2019) “3D finite element model for hybrid FRP-confined concrete in compression using modified CDPM.” Engineering Structures, 190: 459-479.

DOI: 10.1016/j.engstruct.2019.04.027

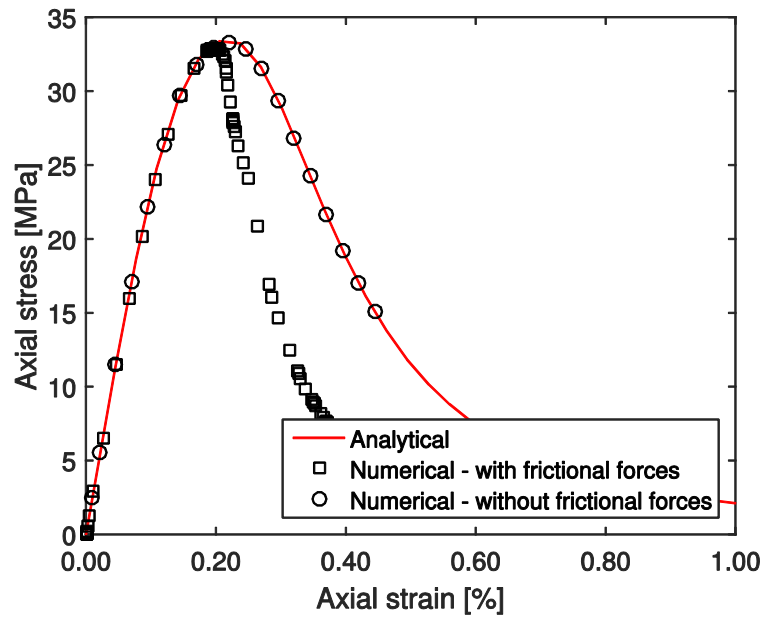

Figure 6 - Evaluation of the effect of end restrains contemplation in the compressive stress-strain curve of plain concrete. 
Ribeiro, F.; Sena-Cruz, J.; Branco, F.; Júlio, E. (2019) “3D finite element model for hybrid FRP-confined concrete in compression using modified CDPM.” Engineering Structures, 190: 459-479.

DOI: 10.1016/j.engstruct.2019.04.027

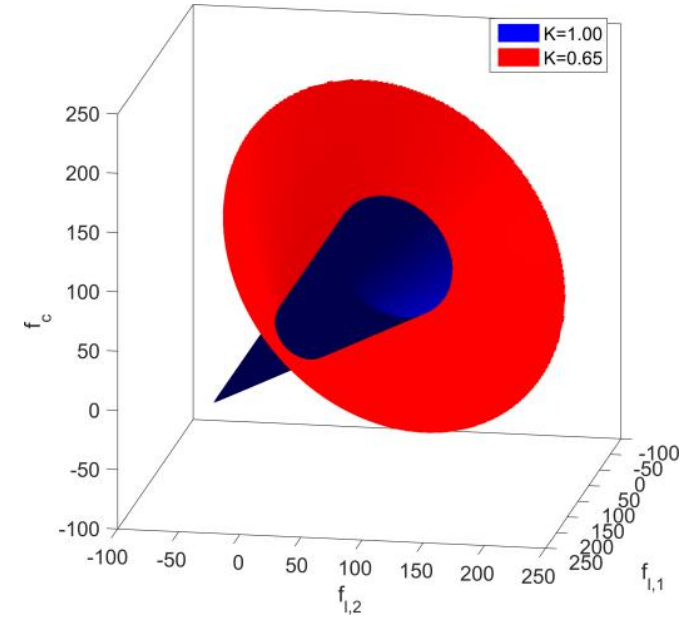

(a)

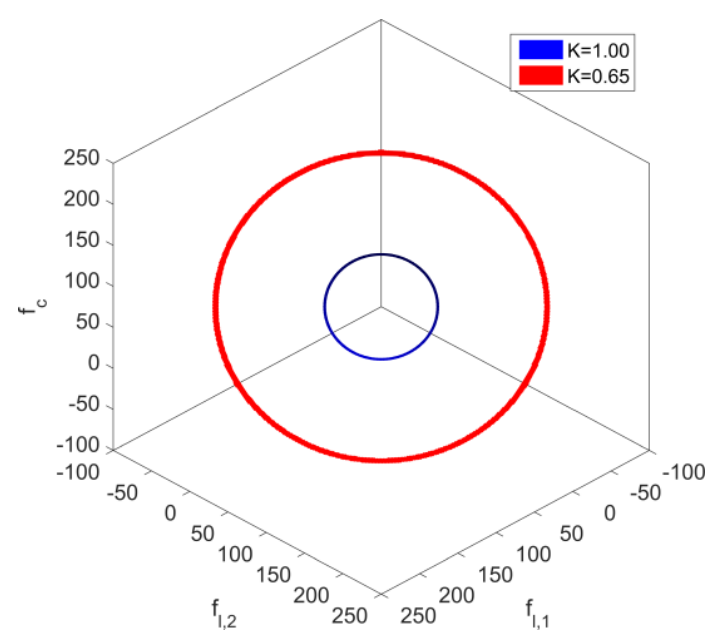

(b)

Figure 7 - Influence of $K$ the yield surface of CDPM: (a) principal stress space and (b) deviatoric plane $\left(\left(f_{\mathrm{c}}+f_{1,1}+f_{1,2}\right) / 3=100\right)$. 
Ribeiro, F.; Sena-Cruz, J.; Branco, F.; Júlio, E. (2019) “3D finite element model for hybrid FRP-confined concrete in compression using modified CDPM.” Engineering Structures, 190: 459-479.

DOI: 10.1016/j.engstruct.2019.04.027

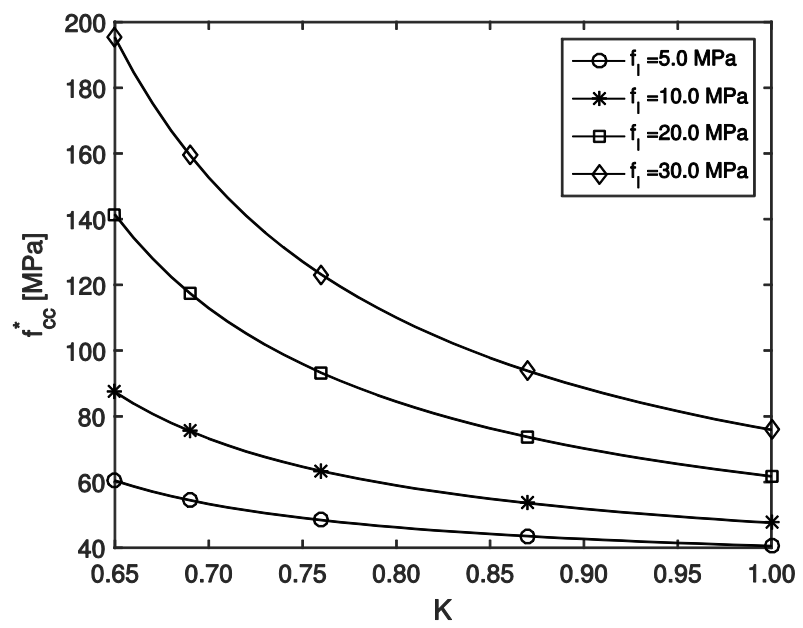

Figure 8 - Peak stress of actively confined concrete in function of $f_{1}$ and $K$. 
Ribeiro, F.; Sena-Cruz, J.; Branco, F.; Júlio, E. (2019) “3D finite element model for hybrid FRP-confined concrete in compression using modified CDPM.” Engineering Structures, 190: 459-479.

DOI: 10.1016/j.engstruct.2019.04.027

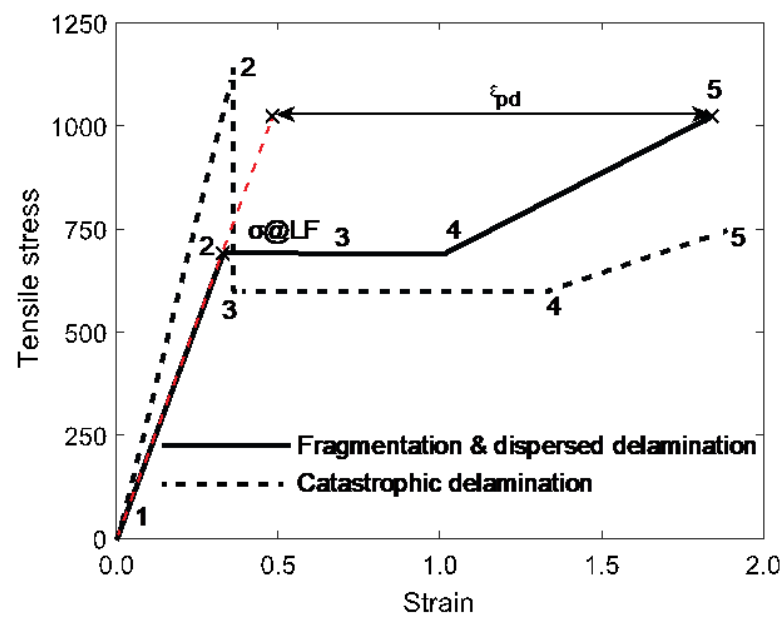

Figure 9 - Tensile nonlinear behaviour of hybrid FRP. 
Ribeiro, F.; Sena-Cruz, J.; Branco, F.; Júlio, E. (2019) “3D finite element model for hybrid FRP-confined concrete in compression using modified CDPM.” Engineering Structures, 190: 459-479.

DOI: 10.1016/j.engstruct.2019.04.027

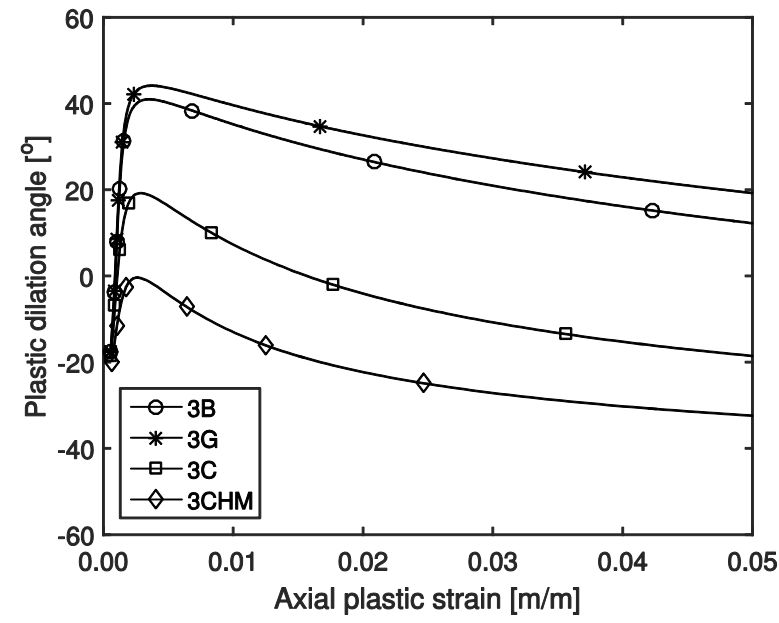

Figure 10 - Plastic dilation angle of non-hybrid FRP-confined concrete in function of axial plastic strain. 
Ribeiro, F.; Sena-Cruz, J.; Branco, F.; Júlio, E. (2019) “3D finite element model for hybrid FRP-confined concrete in compression using modified CDPM.” Engineering Structures, 190: 459-479.

DOI: 10.1016/j.engstruct.2019.04.027

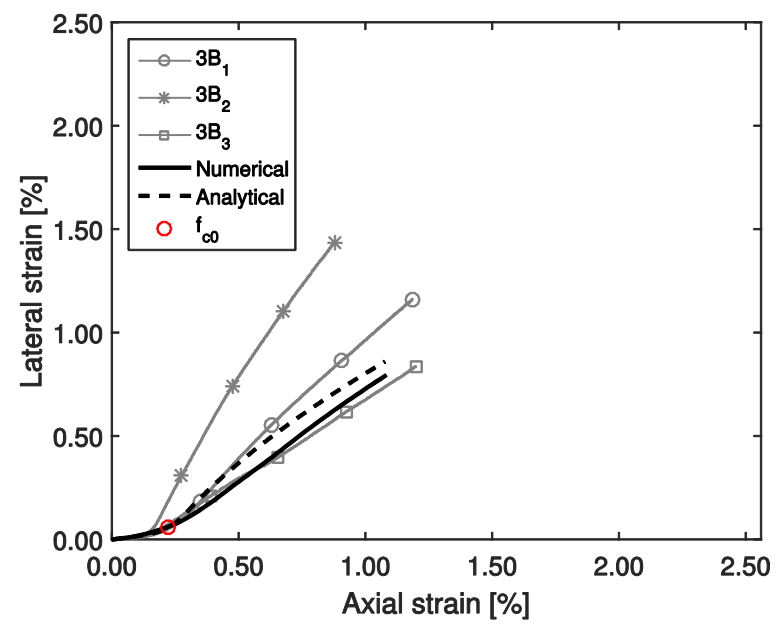

(a)

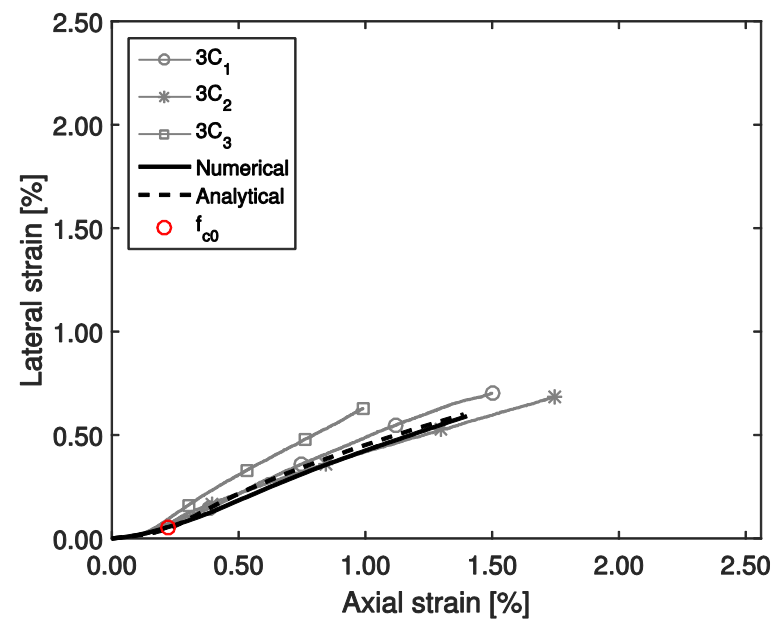

(c)

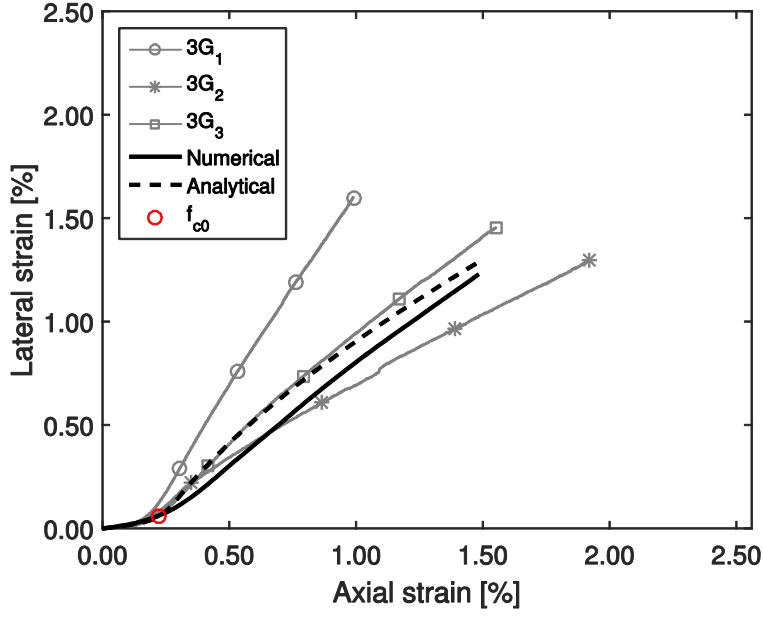

(b)

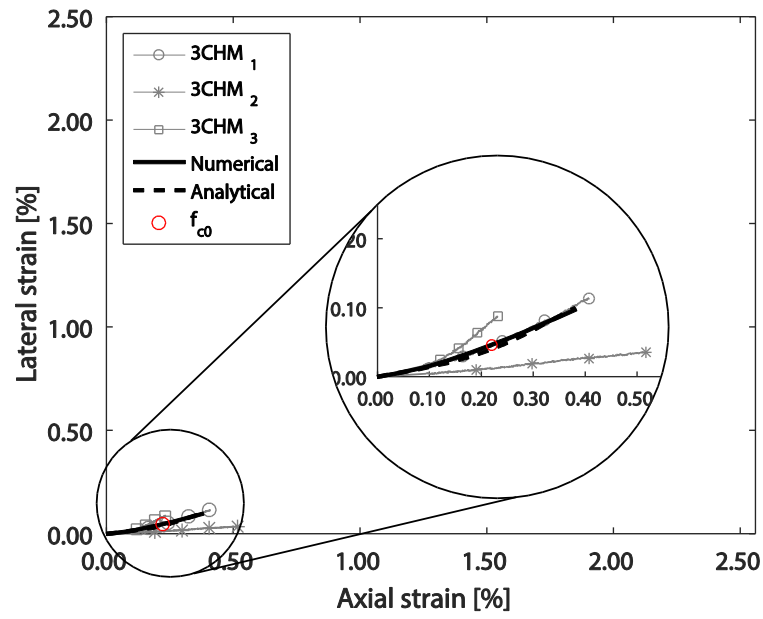

(d)

Figure 11 - Lateral strain-axial strain curves: (a) basalt; (b) glass; (c) ST carbon and (d) HM carbon composite confined concrete. 
Ribeiro, F.; Sena-Cruz, J.; Branco, F.; Júlio, E. (2019) “3D finite element model for hybrid FRP-confined concrete in compression using modified CDPM.” Engineering Structures, 190: 459-479.

DOI: 10.1016/j.engstruct.2019.04.027

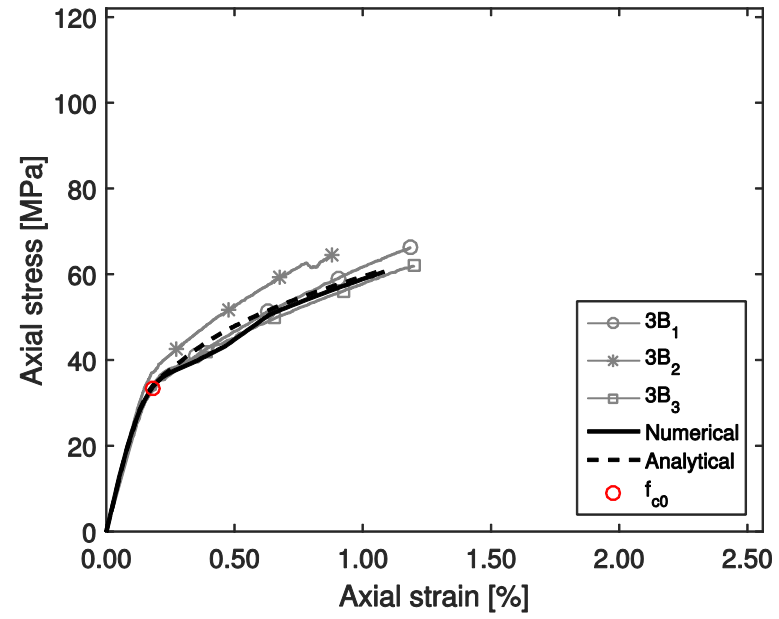

(a)

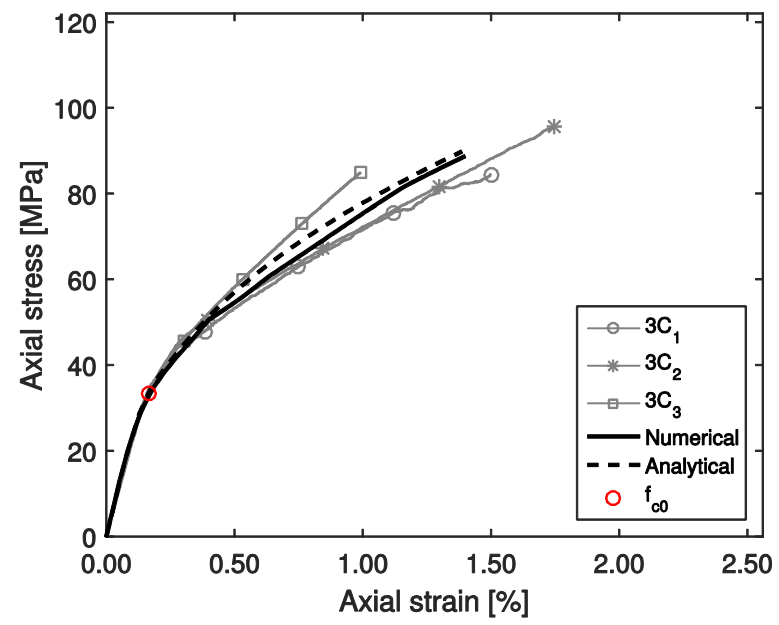

(c)

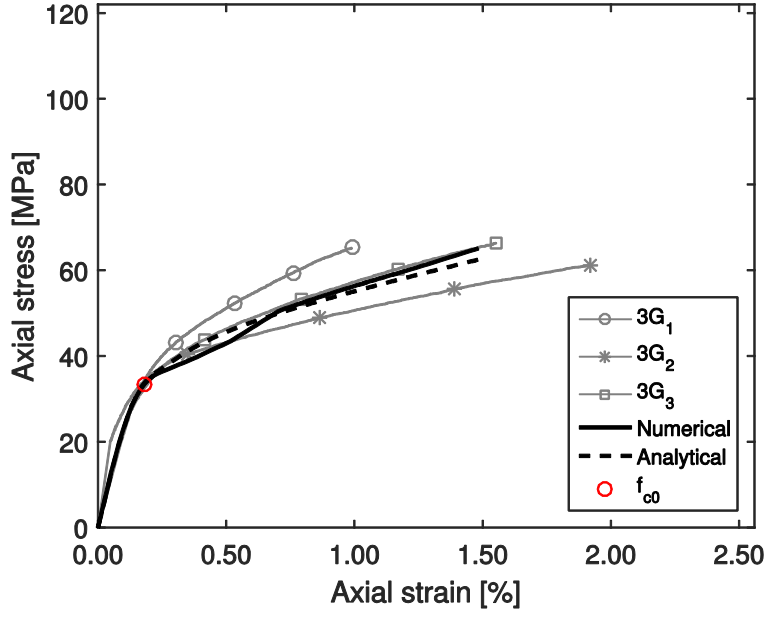

(b)

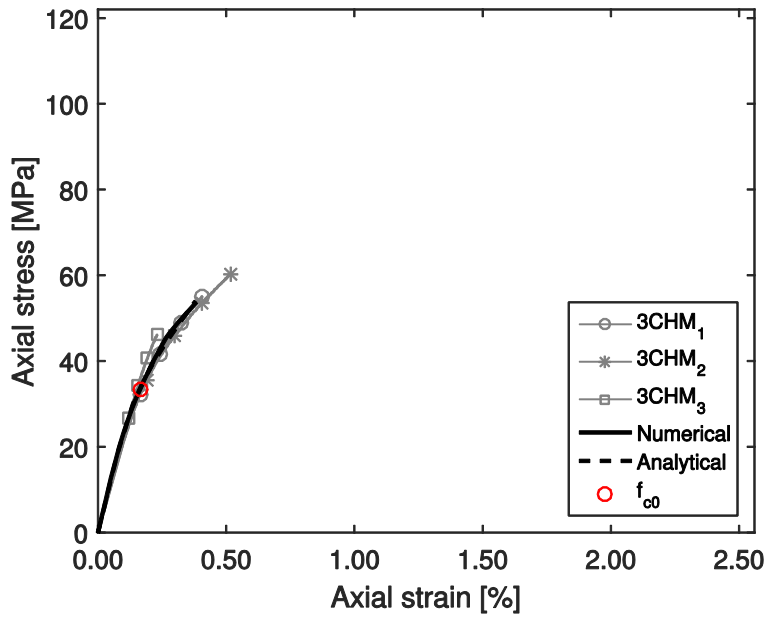

(d)

Figure 12 - Axial stress-strain curves: (a) basalt; (b) glass; (c) ST carbon and (d) HM carbon composite confined concrete. 
Ribeiro, F.; Sena-Cruz, J.; Branco, F.; Júlio, E. (2019) "3D finite element model for hybrid FRP-confined concrete in compression using modified CDPM.” Engineering Structures, 190: 459-479.

DOI: 10.1016/j.engstruct.2019.04.027

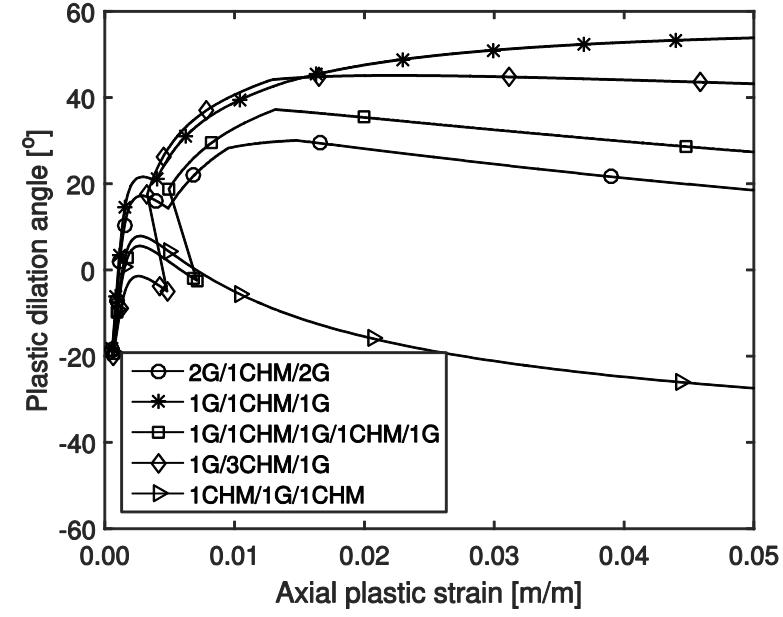

(a)

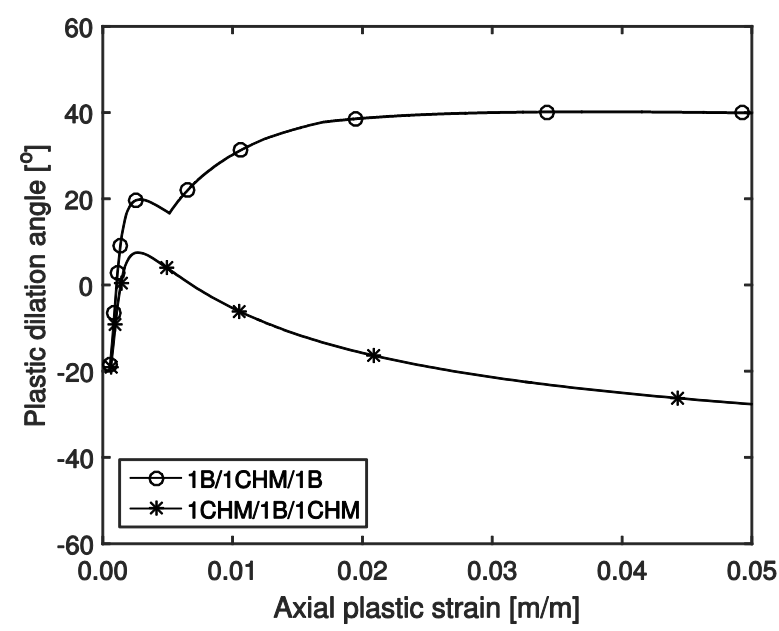

(c)

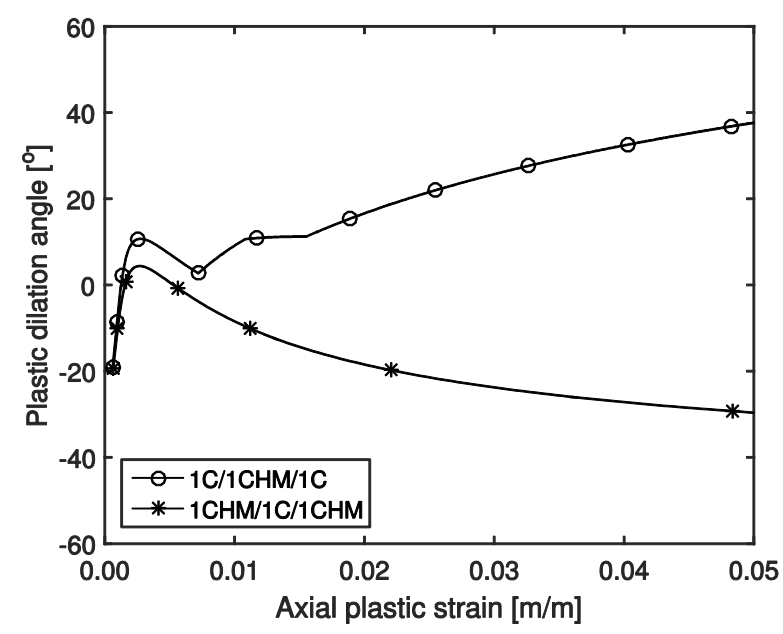

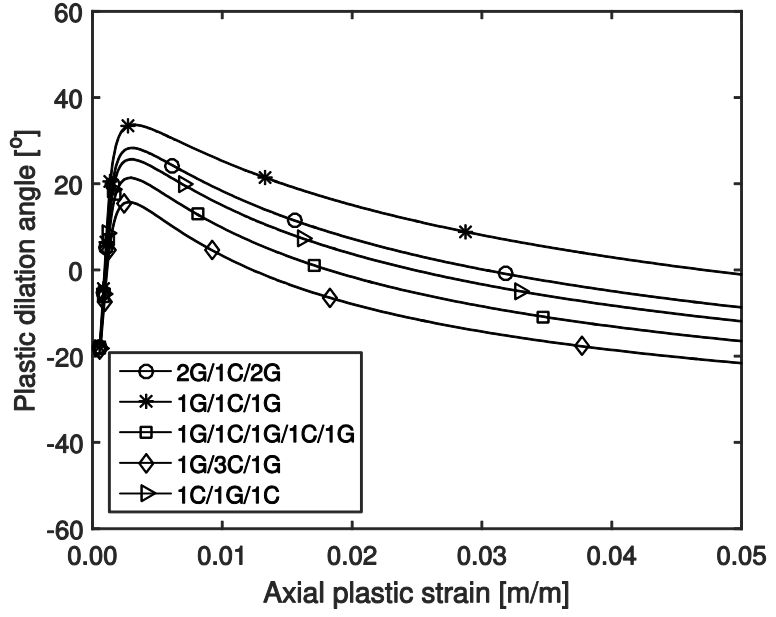

(b)

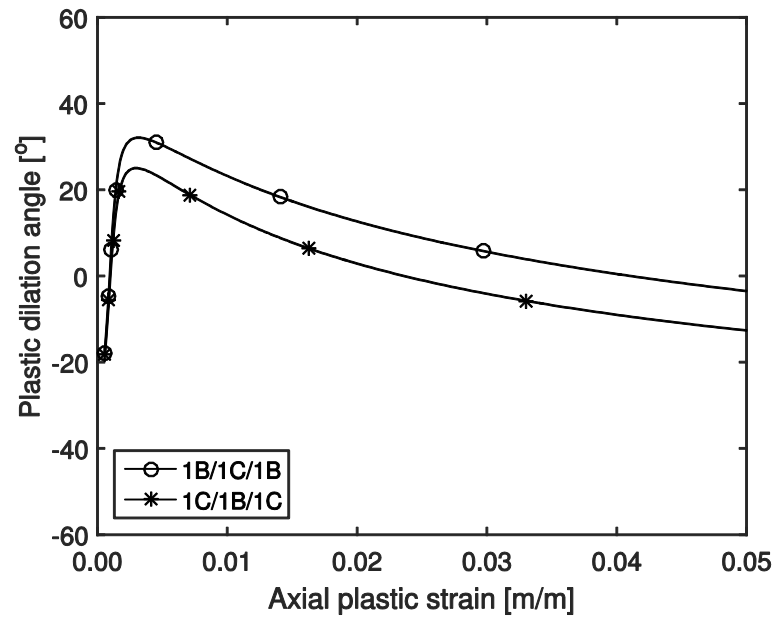

(d)

(e)

Figure 13 - Plastic dilation angle of hybrid FRP-confined concrete in function of axial plastic strain: (a) HM carbon/glass; (b) ST carbon/glass; (c) HM carbon/basalt; (d) ST carbon/basalt and (e) HM carbon/ST carbon composites. 
Ribeiro, F.; Sena-Cruz, J.; Branco, F.; Júlio, E. (2019) “3D finite element model for hybrid FRP-confined concrete in compression using modified CDPM.” Engineering Structures, 190: 459-479.

DOI: 10.1016/j.engstruct.2019.04.027

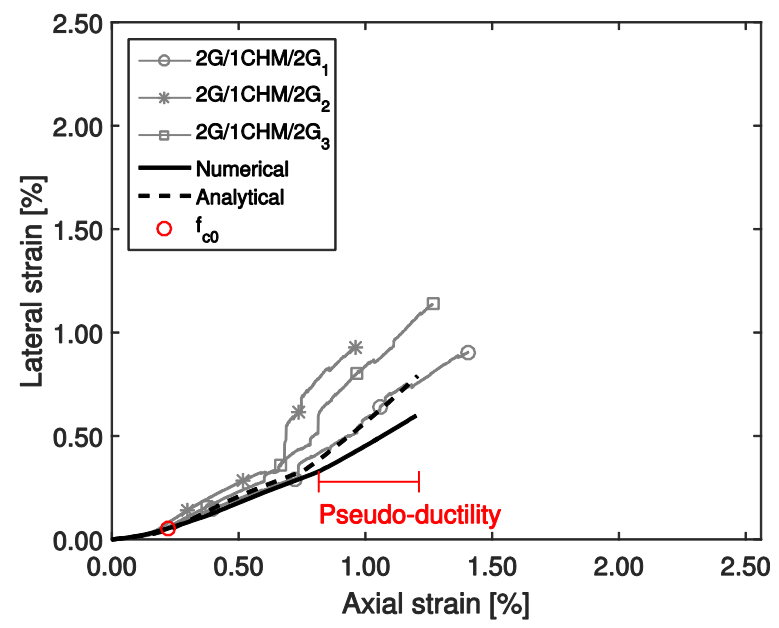

(a)

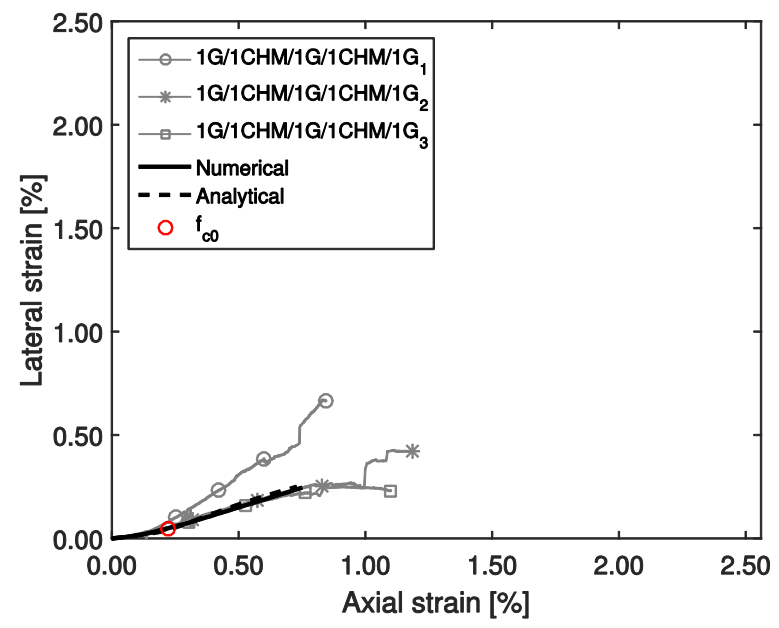

(c)

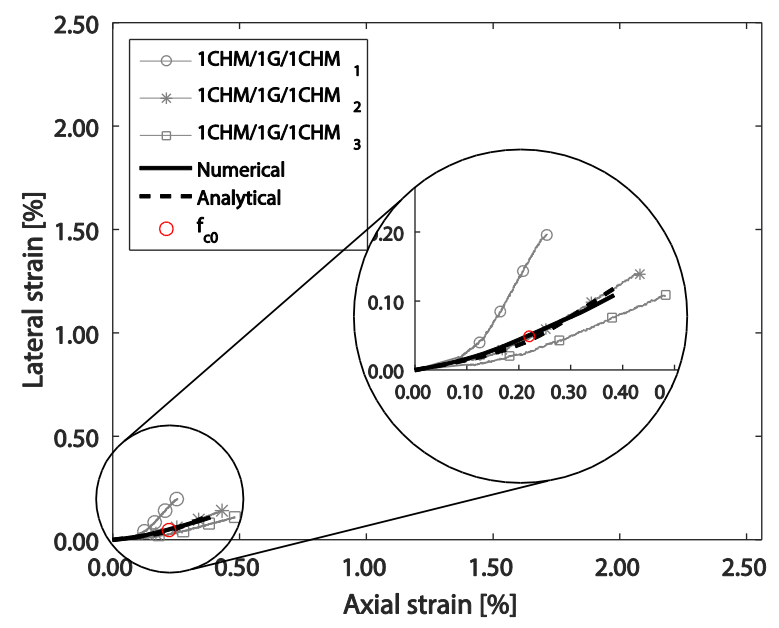

(e)

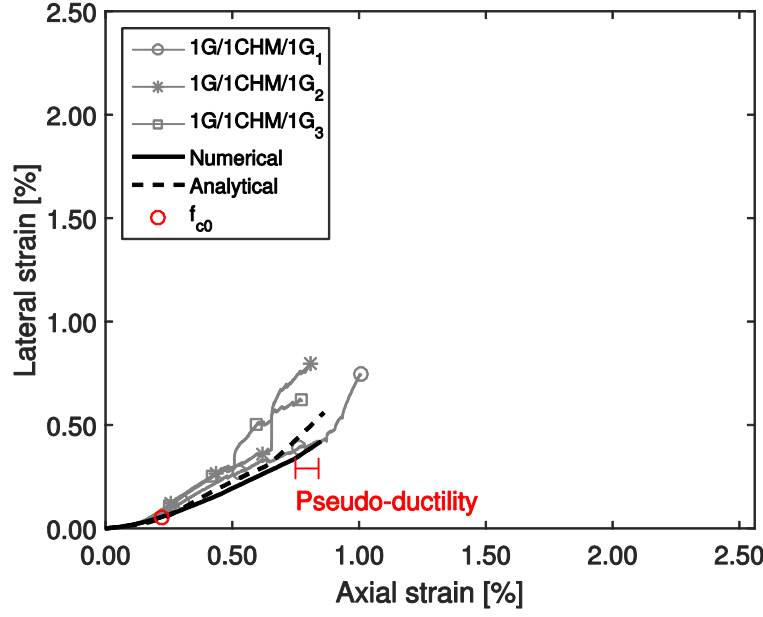

(b)

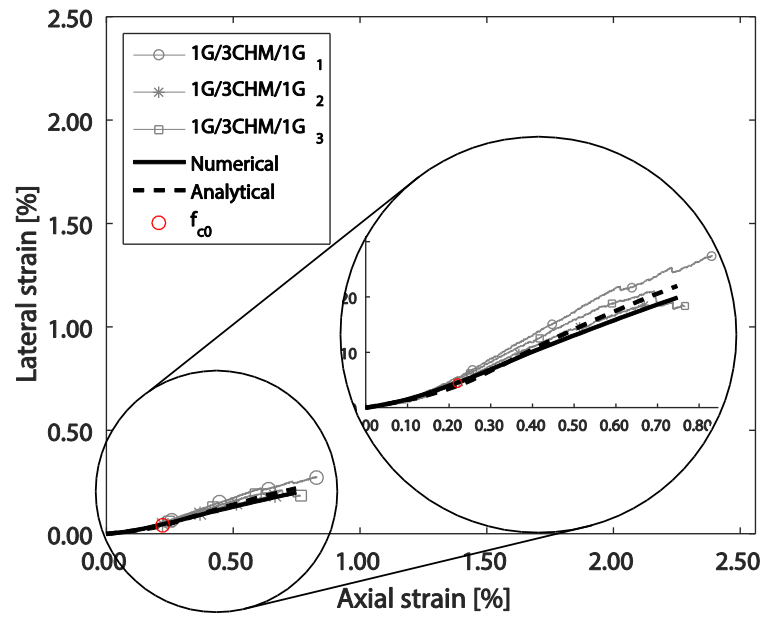

(d) 
Ribeiro, F.; Sena-Cruz, J.; Branco, F.; Júlio, E. (2019) “3D finite element model for hybrid FRP-confined concrete in compression using modified CDPM.” Engineering Structures, 190: 459-479.

DOI: 10.1016/j.engstruct.2019.04.027

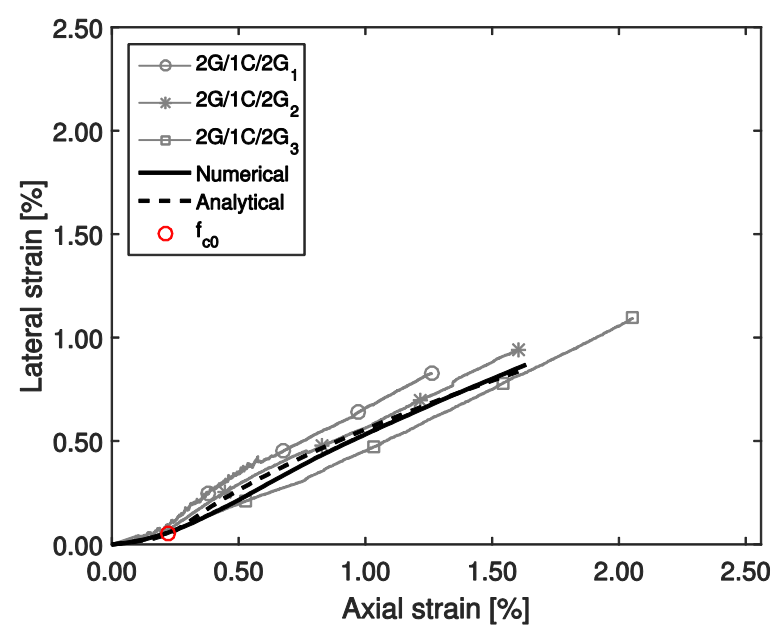

(a)

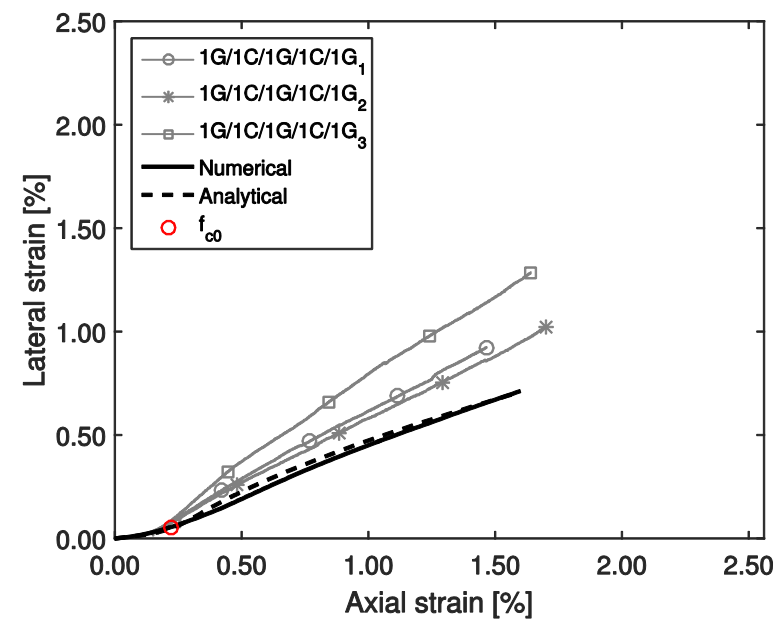

(c)

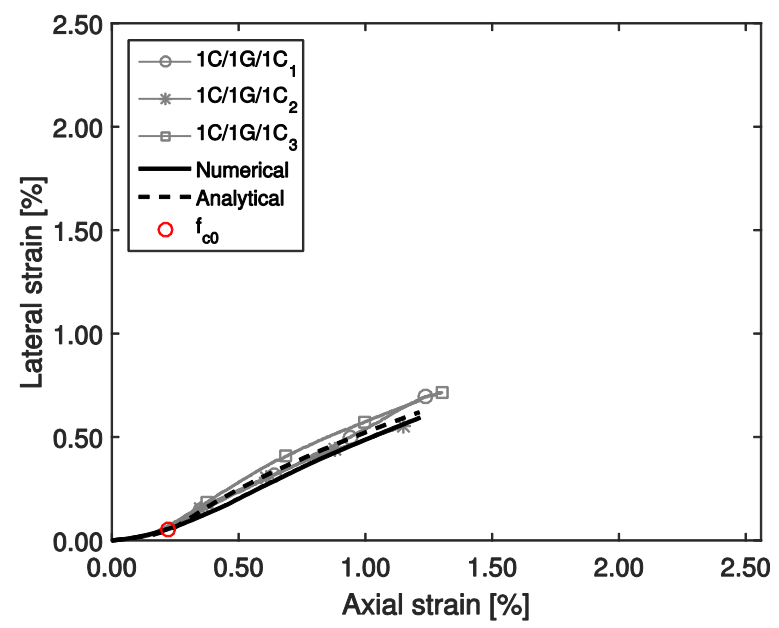

(e)

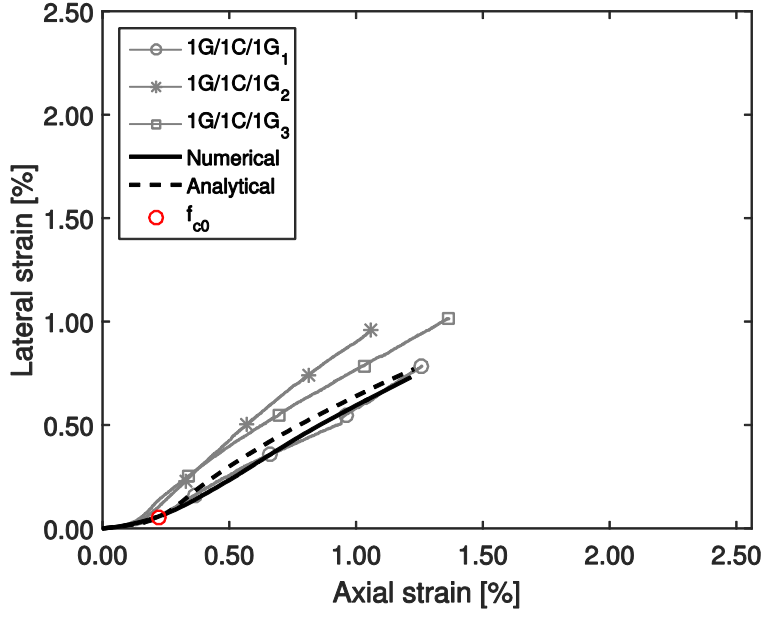

(b)

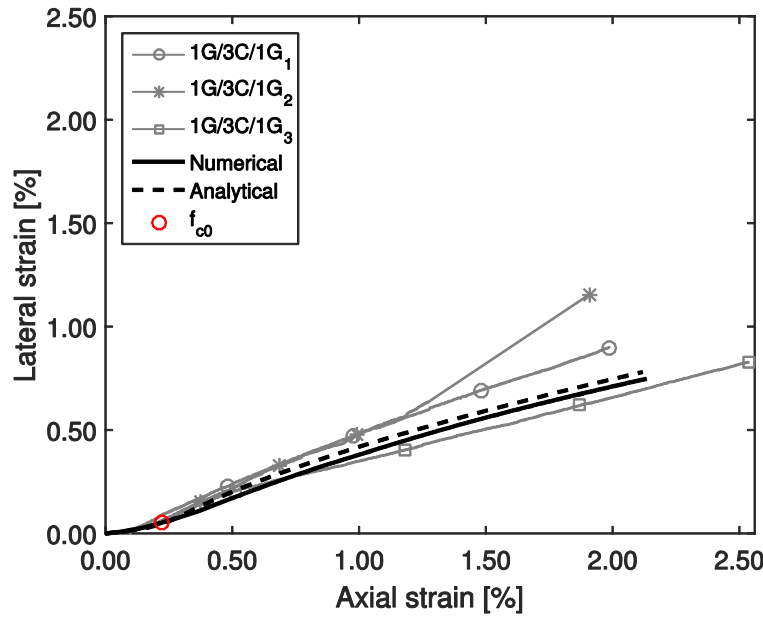

(d)

Figure 15 - Lateral strain-axial strain curves of $\mathrm{C} / \mathrm{G}$ combinations: experimental versus predicted values. 
Ribeiro, F.; Sena-Cruz, J.; Branco, F.; Júlio, E. (2019) “3D finite element model for hybrid FRP-confined concrete in compression using modified CDPM.” Engineering Structures, 190: 459-479.

DOI: 10.1016/j.engstruct.2019.04.027

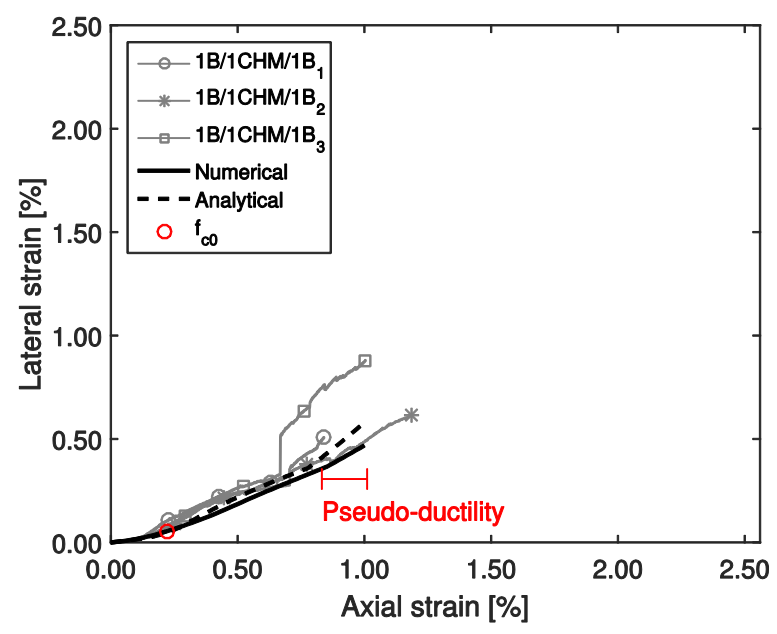

(a)

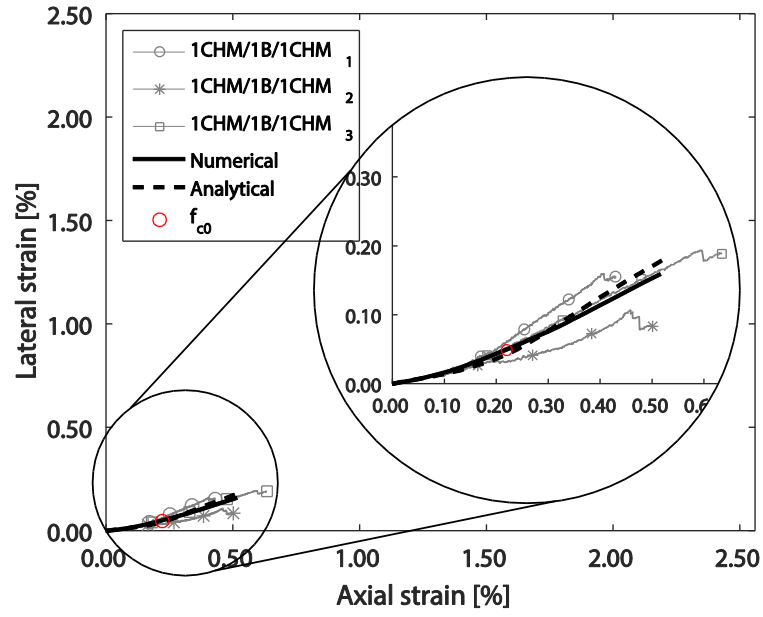

(b)

Figure 16 - Lateral strain-axial strain curves of CHM/B combinations: experimental versus predicted values. 
Ribeiro, F.; Sena-Cruz, J.; Branco, F.; Júlio, E. (2019) “3D finite element model for hybrid FRP-confined concrete in compression using modified CDPM.” Engineering Structures, 190: 459-479.

DOI: 10.1016/j.engstruct.2019.04.027

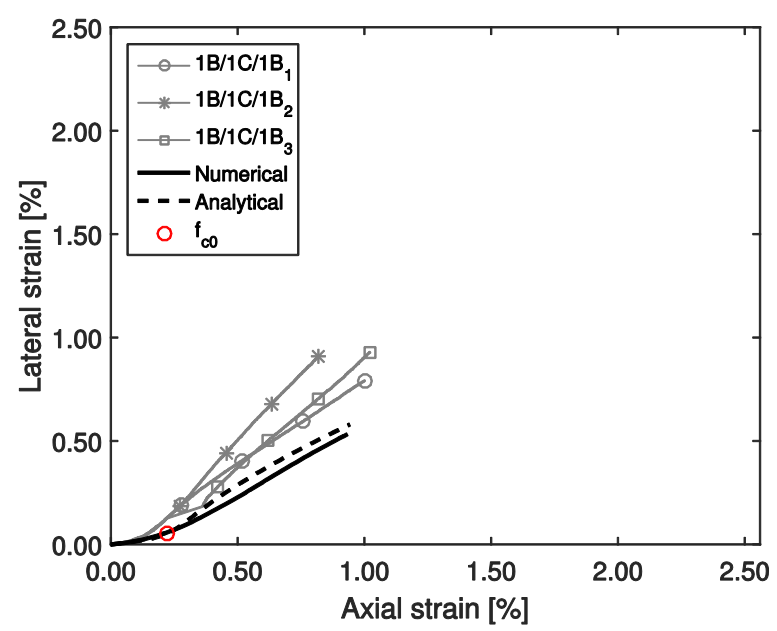

(a)

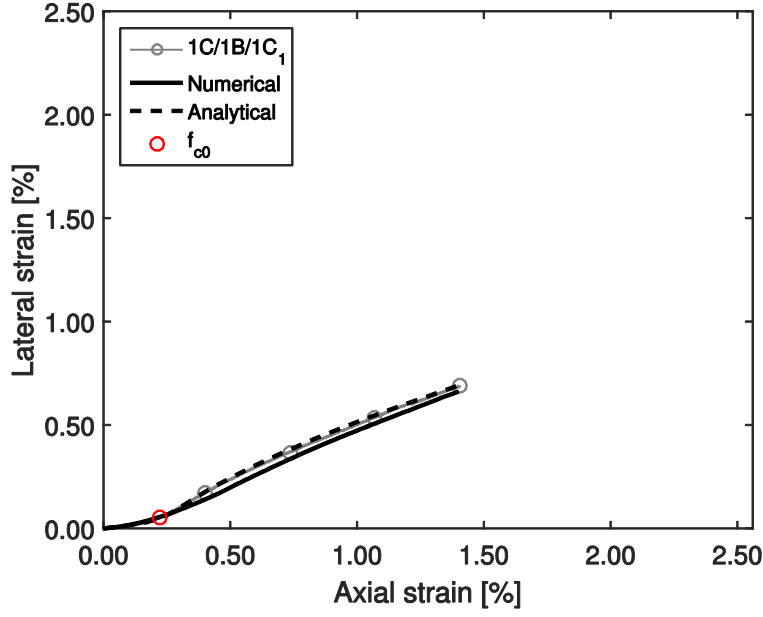

(b)

Figure 17 - Lateral strain-axial strain curves of C/B combinations: experimental versus predicted values. 
Ribeiro, F.; Sena-Cruz, J.; Branco, F.; Júlio, E. (2019) “3D finite element model for hybrid FRP-confined concrete in compression using modified CDPM.” Engineering Structures, 190: 459-479.

DOI: 10.1016/j.engstruct.2019.04.027

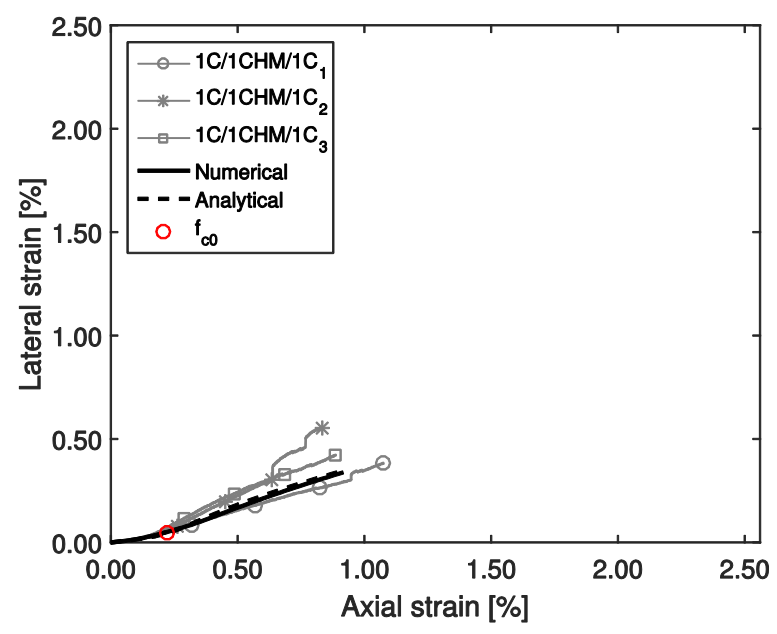

(a)

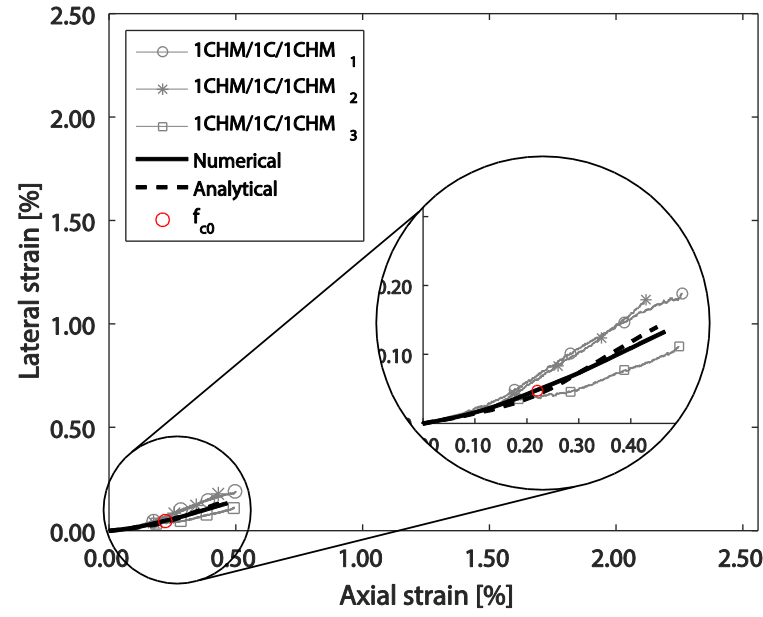

(b)

Figure 18 - Lateral strain-axial strain curves of CHM/C combinations: experimental versus predicted values. 
Ribeiro, F.; Sena-Cruz, J.; Branco, F.; Júlio, E. (2019) “3D finite element model for hybrid FRP-confined concrete in compression using modified CDPM.” Engineering Structures, 190: 459-479.

DOI: 10.1016/j.engstruct.2019.04.027

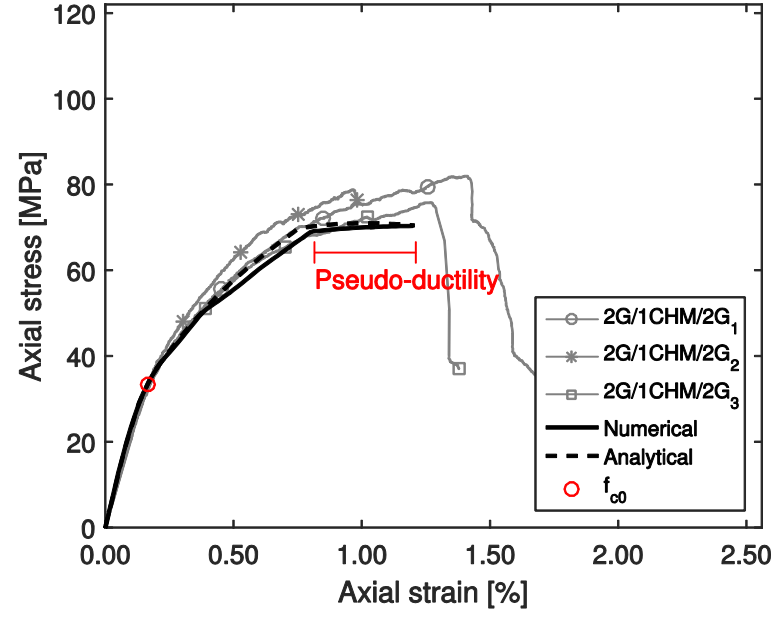

(a)

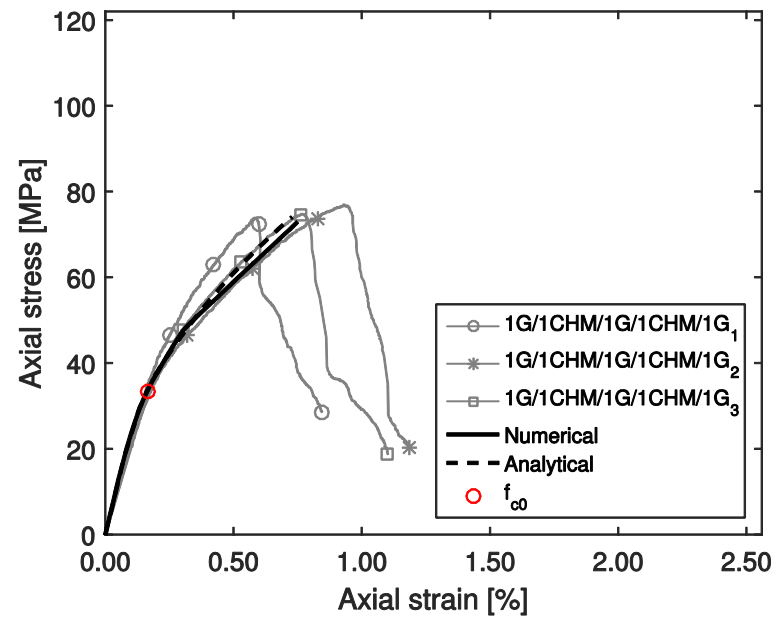

(c)

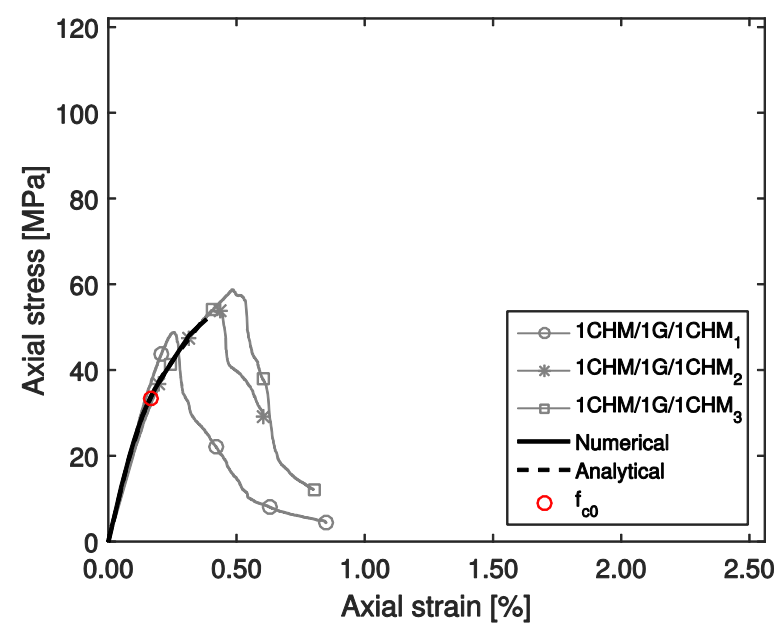

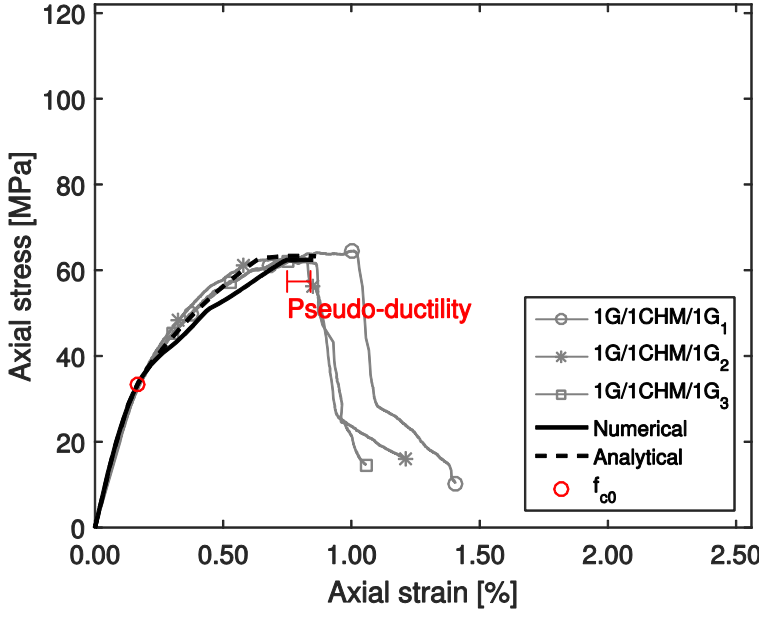

(b)

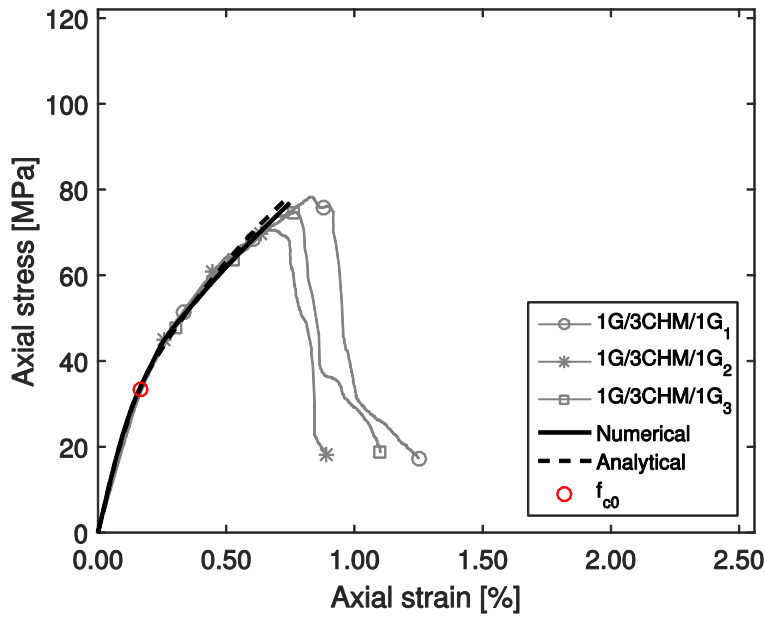

(d)

(e)

Figure 19 - Stress-strain curves of CHM/G combinations: experimental versus predicted values. 
Ribeiro, F.; Sena-Cruz, J.; Branco, F.; Júlio, E. (2019) “3D finite element model for hybrid FRP-confined concrete in compression using modified CDPM.” Engineering Structures, 190: 459-479.

DOI: 10.1016/j.engstruct.2019.04.027

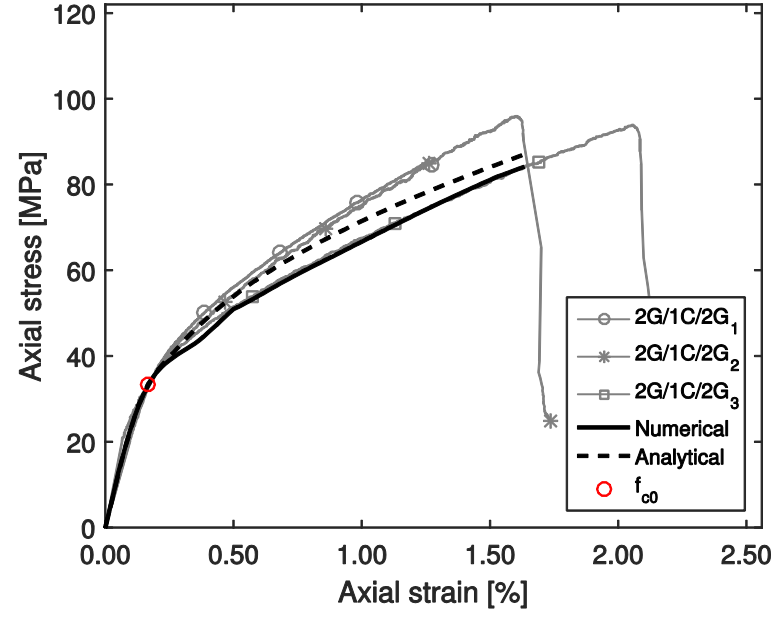

(a)

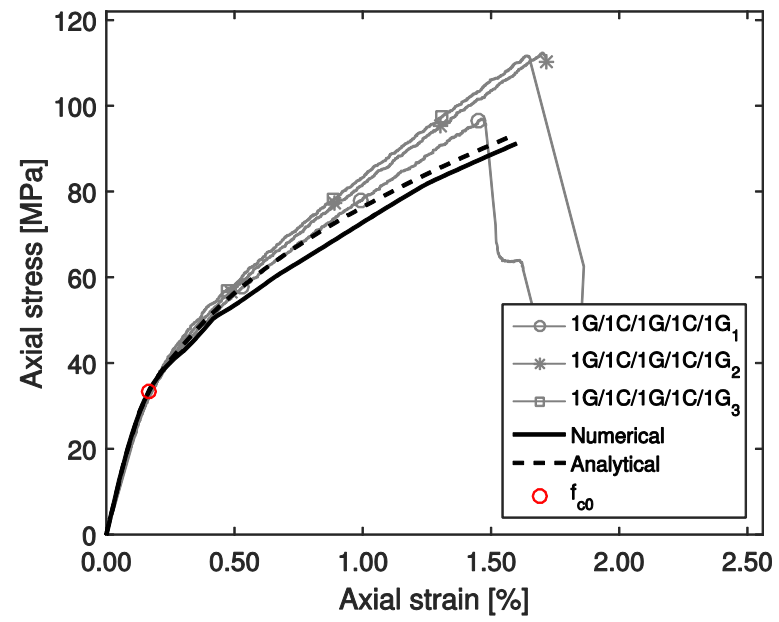

(c)

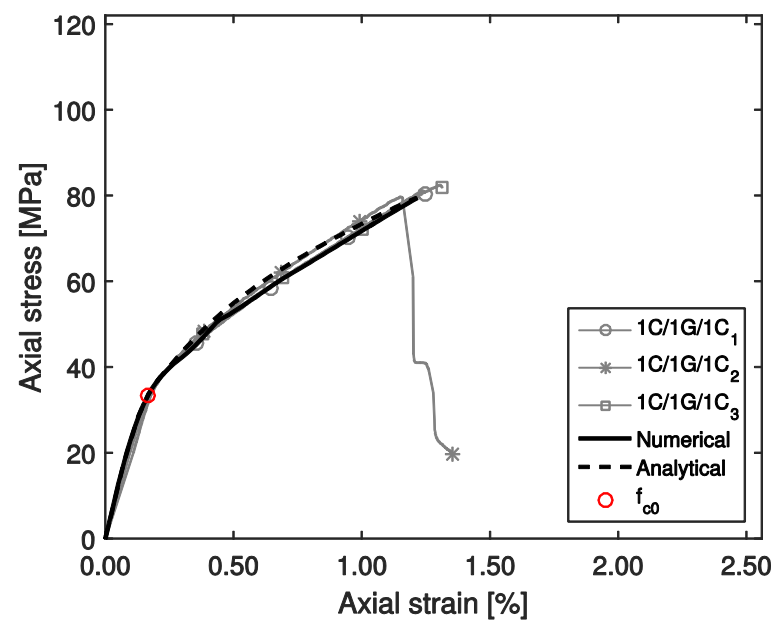

(e)

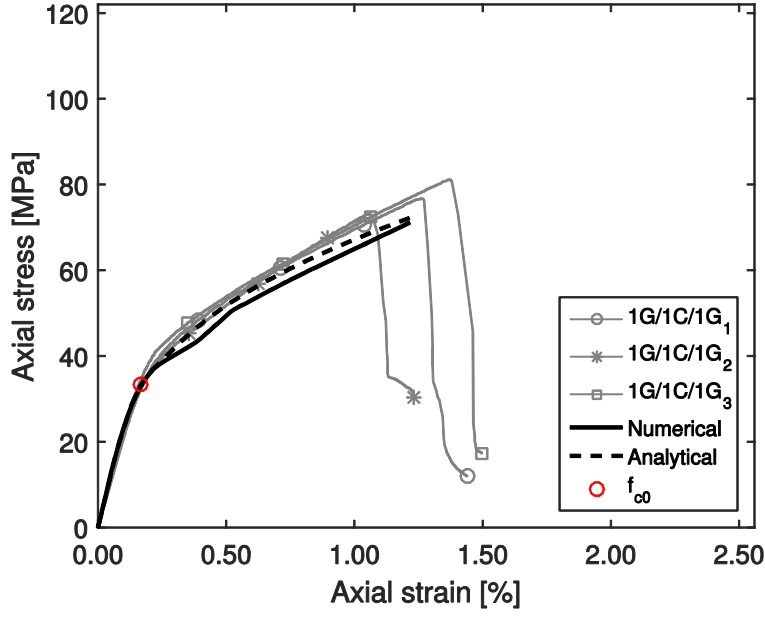

(b)

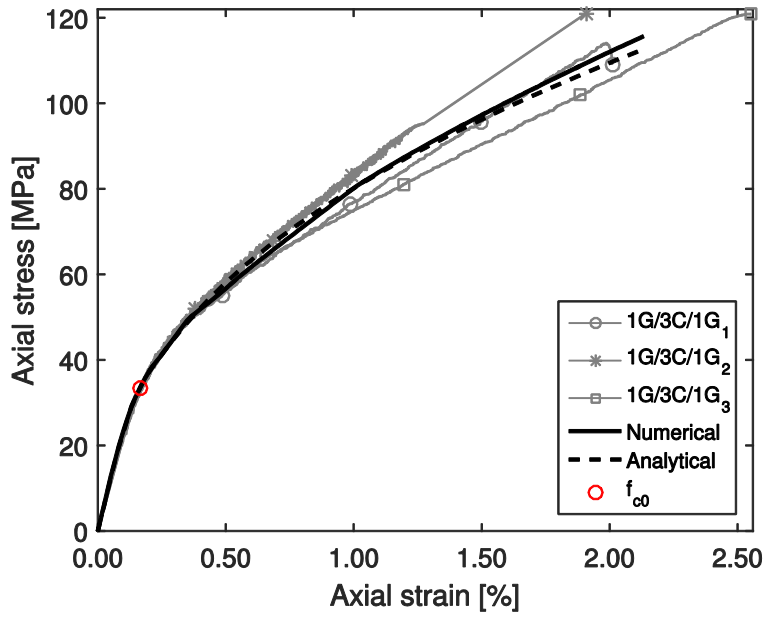

(d)

Figure 20 - Stress-strain curves of $\mathrm{C} / \mathrm{G}$ combinations: experimental versus predicted values. 
Ribeiro, F.; Sena-Cruz, J.; Branco, F.; Júlio, E. (2019) “3D finite element model for hybrid FRP-confined concrete in compression using modified CDPM.” Engineering Structures, 190: 459-479.

DOI: 10.1016/j.engstruct.2019.04.027

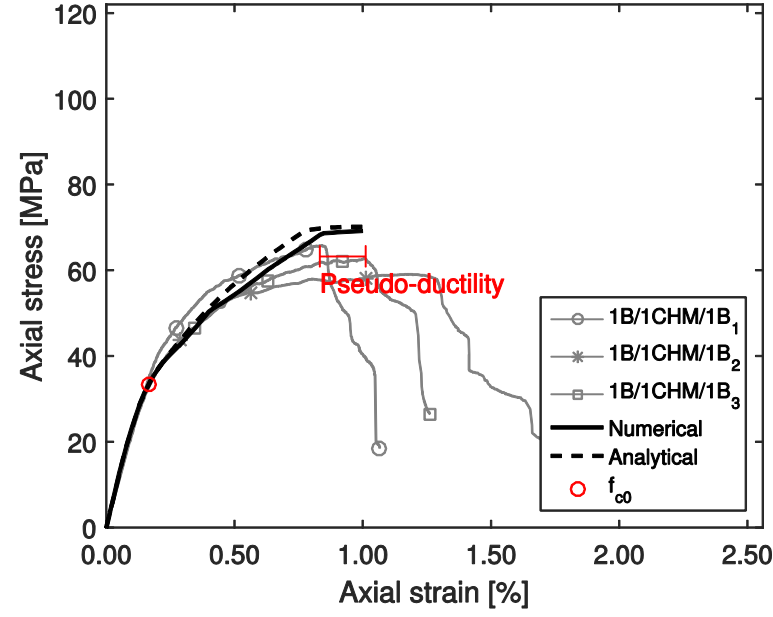

(a)

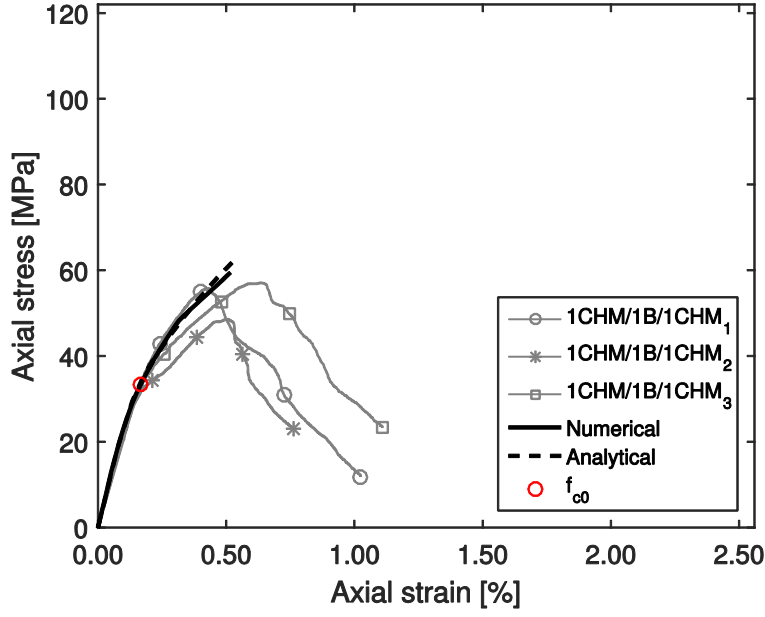

(b)

Figure 21 - Stress-strain curves of CHM/B combinations: experimental versus predicted values. 
Ribeiro, F.; Sena-Cruz, J.; Branco, F.; Júlio, E. (2019) “3D finite element model for hybrid FRP-confined concrete in compression using modified CDPM.” Engineering Structures, 190: 459-479.

DOI: 10.1016/j.engstruct.2019.04.027

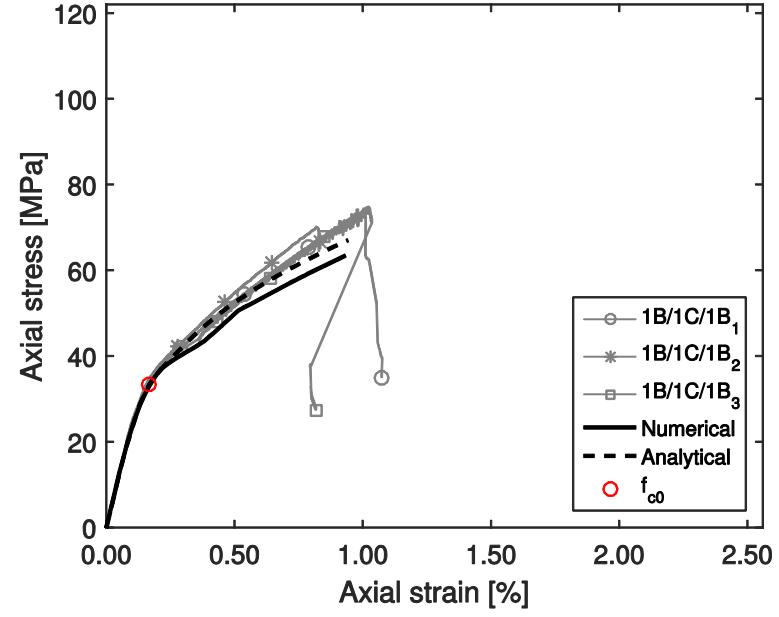

(a)

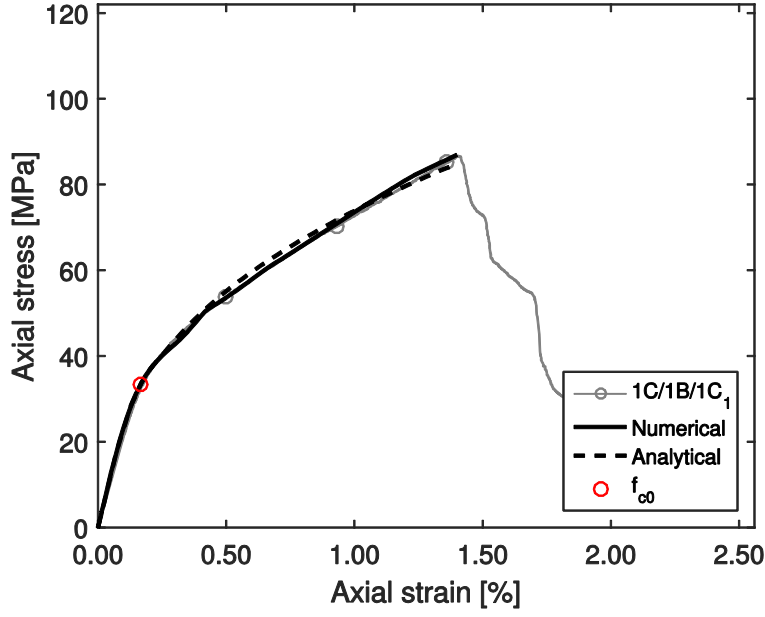

(b)

Figure 22 - Stress-strain curves of C/B combinations: experimental versus predicted values. 
Ribeiro, F.; Sena-Cruz, J.; Branco, F.; Júlio, E. (2019) “3D finite element model for hybrid FRP-confined concrete in compression using modified CDPM.” Engineering Structures, 190: 459-479.

DOI: 10.1016/j.engstruct.2019.04.027

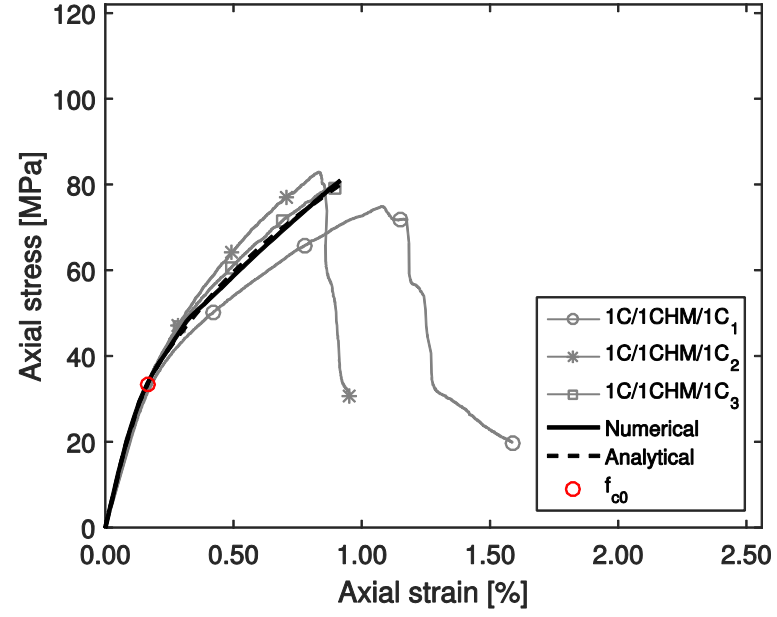

(a)

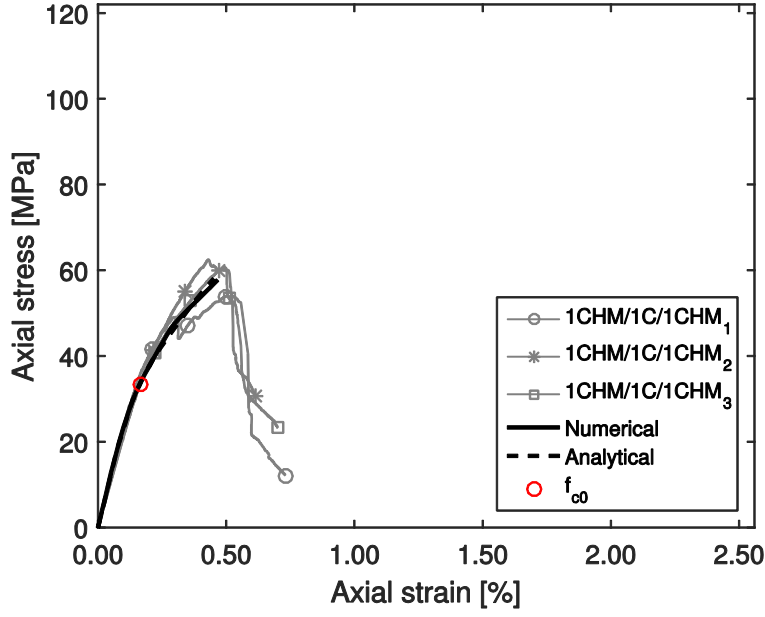

(b)

Figure 23 - Stress-strain curves of CHM/C combinations: experimental versus predicted values. 